Portland State University

PDXScholar

11-3-1995

\title{
Influence of Heater Orientation on Fluctuations in Steady-state Nucleate Boiling
}

William F. Osborne

Portland State University

Follow this and additional works at: https://pdxscholar.library.pdx.edu/open_access_etds

Part of the Speech and Rhetorical Studies Commons

Let us know how access to this document benefits you.

\section{Recommended Citation}

Osborne, William F., "Influence of Heater Orientation on Fluctuations in Steady-state Nucleate Boiling" (1995). Dissertations and Theses. Paper 4958.

https://doi.org/10.15760/etd.6834

This Thesis is brought to you for free and open access. It has been accepted for inclusion in Dissertations and Theses by an authorized administrator of PDXScholar. Please contact us if we can make this document more accessible: pdxscholar@pdx.edu. 


\section{THESIS APPROVAL}

The abstract and thesis of William F. Osborne for the Master of Science in Physics were presented November 3,1995, and accepted by the thesis committee and the department.

COMMITTEE APPROVALS:

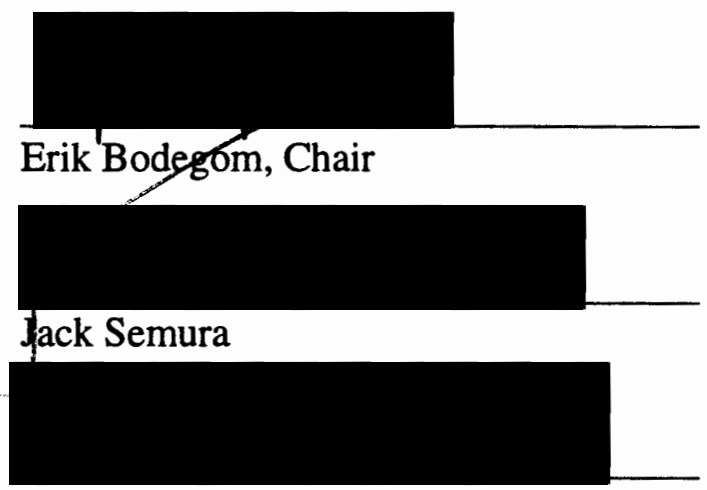

Laird C. Brodie

DEPARTMENTAL APPROVAL:

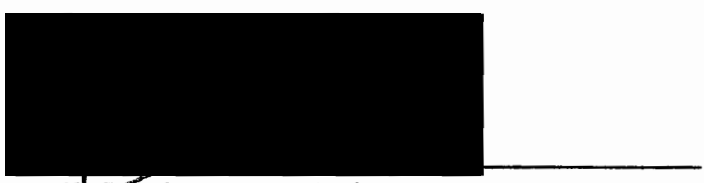

Erik Bodegom, Chair

Department of Physics

$* * * * * * * * * * * * * * * * * * * * * * * * * * * * * * * * * * * * * * * * * * * * * * * * * * * * * * * * * * * * * * * * * * * * * *$ 


\begin{abstract}
An abstract of the thesis of William F. Osborne for the Master of Science in Physics presented November 3, 1995.
\end{abstract}

Title: Influence of heater orientation on fluctuations in steady-state nucleate boiling.

In observations of steady-state nucleate boiling, fluctuations in the temperature and heat flux might initially appear to be completely random. However, it was shown that, for a vertically mounted platinum wire in liquid nitrogen, the fluctuations about the steady-state exhibit an average counterclockwise circulation when the heat flux is plotted versus the superheat temperature. An area associated with the average circulation was proposed as a numerical measure of stability for steady-state nucleate boiling. The mechanisms for the generation of these fluctuations are thought to be the feedback of the bubbles rising past the wire and the differential heating and cooling that this engenders. Data similar to the data on the vertical wire have been obtained using the same wire mounted horizontally. Although the counterclockwise circulation mentioned above is still seen, the measure of stability as proposed earlier, is less useful for prediction of the 
transition to film boiling. This reduced sensitivity can be attributed to the fact that the possibility of feedback through the rising bubbles has been eliminated. 
INFLUENCE OF HEATER ORIENTATION ON FLUCTUATIONS IN STEADY-STATE NUCLEATE BOILING

\author{
by \\ WILLIAM F. OSBORNE
}

A thesis submitted in partial fulfillment of the requirements for the degree of

\title{
MASTER OF SCIENCE \\ in \\ PHYSICS
}

Portland State University

1995 


\section{ACKNOWLEDGMENTS}

I would like to thank Erik Bodegom, Laird Brodie and Jack Semura. All were very helpful with this project. I would also like to thank everyone in the Physics

depatrment. During my time at PSU, they have all helped me at some point. Finally, I would like to thank everyone I have ever met in my life. Since a person's abilities and personality is a sum of their experiences, this paper has many contributors. 
TABLE OF CONTENTS

PAGE

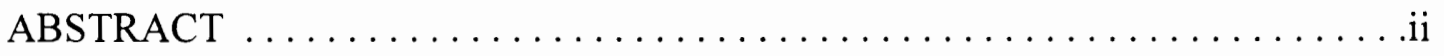

ACKNOWLEDGEMENTS $\ldots \ldots \ldots \ldots \ldots \ldots \ldots \ldots \ldots \ldots \ldots \ldots \ldots$ iv

LIST OF FIGURES $\ldots \ldots \ldots \ldots \ldots \ldots \ldots \ldots \ldots \ldots \ldots \ldots \ldots \ldots \ldots \ldots \ldots \ldots$

\section{CHAPTER}

$1 \quad$ INTRODUCTION $\ldots \ldots \ldots \ldots \ldots \ldots \ldots \ldots \ldots \ldots \ldots \ldots \ldots \ldots \ldots$

Background $\ldots \ldots \ldots \ldots \ldots \ldots \ldots \ldots \ldots \ldots \ldots \ldots \ldots \ldots \ldots \ldots \ldots$

Apparatus Overview........................ 2

Synchronization $\ldots \ldots \ldots \ldots \ldots \ldots \ldots \ldots \ldots \ldots \ldots$

Heat Transfer Characreristics . . . . . . . . . . . . . . . 5

2 EXPERIMENTAL SETUP $\ldots \ldots \ldots \ldots \ldots \ldots \ldots \ldots \ldots$

Apparatus Description .......................... 9

Data Collection Procedure $\ldots \ldots \ldots \ldots \ldots \ldots \ldots \ldots$

Thermal Time Constant ...................... 13 
Typical Data Collection ........................14

3 RESULTS AND DISCUSSION $\ldots \ldots \ldots \ldots \ldots \ldots \ldots \ldots \ldots$

Raw Data Analysis......................... 15

Platinum Wire Resistance $\ldots \ldots \ldots \ldots \ldots \ldots \ldots$

Fast Fourier Transformations . . . . . . . . . . . . . . 16

Circulation Analysis . . . . . . . . . . . . . . . . . . 17

Data Analysis Comparisions. . . . . . . . . . . . . . . 18

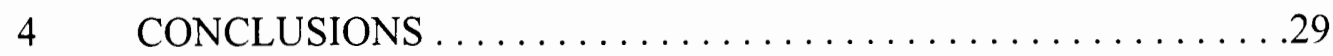

REFERENCES. . . . . . . . . . . . . . . . . . . 32

\section{APPENDIX}

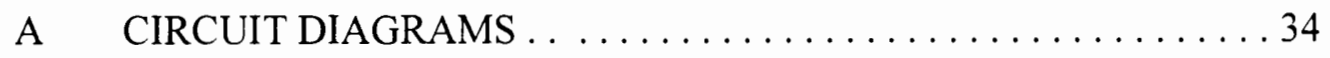

B LISTING OF COMPUTER PROGRAM $\ldots \ldots \ldots \ldots \ldots \ldots . . \ldots \ldots$ 


\section{LIST OF FIGURES}

FIGURE

PAGE

1. Synchronization caused by bubbles moving in a convective current . . . 3

2. Typical Fluctuations About the Average in the Temperature-

Heat Flux Plane $\ldots \ldots \ldots \ldots \ldots \ldots \ldots \ldots \ldots \ldots \ldots \ldots$

3. Experimental Apparatus . . . . . . . . . . . . . . . . . . 12

4. One Second Horizontal Temperature Data . . . . . . . . . . . . . . . 19

5. One Second Vertical Temperature Data. . . . . . . . . . . . . . 20

6. 50 Millisecond Comparision of Vertical and Horizontal Temperature

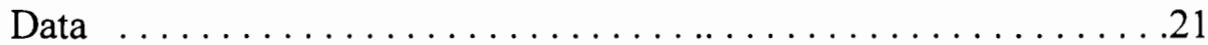

7. Platinum Wire Resistance versus Applied Steady Current . . . . . . . 22

8. 4096 Point Fast Fourier Transformation of Vertical Data . . . . . . . . . 23

9. 4096 Point Fast Fourier Transformation of Horizontal Data . . . . . . . 24

10. Circulation in the Heat Flux-Temperature Plane Versus the

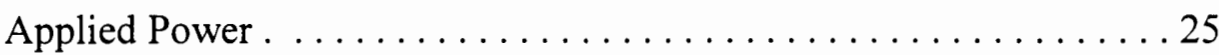

11. Circulation in the Heat Flux-Temperature Plane Versus the

Applied Power with a Quartic Curve Fit Line Added. 


\section{CHAPTER 1 INTRODUCTION}

\section{BACKGROUND}

Heat dissipation is a primary factor in the design of any temperature sensitive system and is often achieved by immersing an object in a cryogenic liquid. The boiling of the liquid allows the transfer of heat from the immersed object to the cryogen. Research involving heat flux and superheat temperatures have helped identify quantities such as the critical heat flux (CHF) for different materials. ${ }^{1,2,3}$ Geometry, cryogen type, and it turns out, spatial orientation all play a role in determining the critical heat flux of a system. This investigation, along with previous research, 4,5 indicates that although the applied power is steady, the temperature of a heater/thermometer can undergo significant fluctuations. The conclusions of Roth et al. ${ }^{4,5}$ were not totally certain and it was thought that more investigation was needed. The intent of this research was threefold. First, we attempted to recreate previous results involving a vertically mounted platinum wire. 
That research had suggested a possible measure as a predictor for the transition from nucleate to film boiling. Second, we investigated the properties of a horizontally mounted wire and compared the results with the vertically mounted wire. Finally, we have clarified the use of the predictor in the transition to film boiling.

\section{APPARATUS OVERVIEW}

An apparatus was built to rotate the platinum wire from the vertical to a horizontal orientation without having to remove the wire from the liquid nitrogen bath. This small change shed new light on the heat flux near a platinum wire. The ability to rotate the wire revealed differences in temperature fluctuations between the horizontal and vertical orientations. For the same applied power, a horizontally oriented wire had significantly smaller temperature fluctuations than the same wire mounted vertically. This result was not unexpected, but the difference was considerable. We suspected that the phenomenon of synchronization was at the root of the difference in temperature fluctuations between horizontal and vertical orientations. 


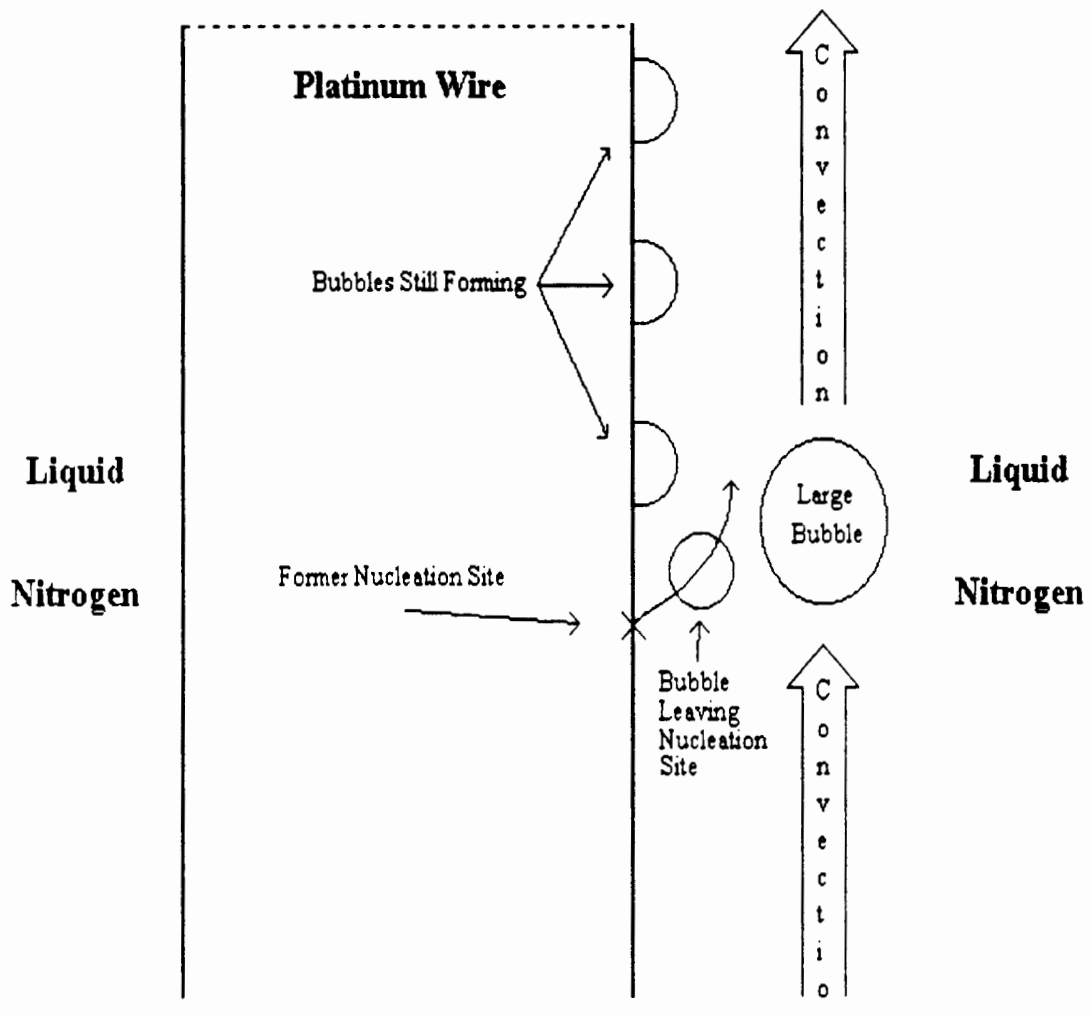

Figure 1. Synchronization caused by bubbles moving in a convective current sweep bubbles still forming on the wire. 


\section{SYNCHRONIZATION}

Synchronization is the process where a bubble released on a lower portion of a vertically mounted wire rises past higher points on the wire. The bubble rising upwards causes a convective current in the liquid nitrogen near the wire. When this bubble passes near another bubble that is still attached to the wire, either the bubbles collide and form an even larger bubble or the attached bubble is pulled from its site (Figure 1). In either case there is a change in wire temperature. This process continues as the bubbles move up the wire causing even more bubbles to detach from the wire. The result is a sweeping action separating most of bubbles from the wire. As a result, there is a sharp decrease in the temperature of the wire.

The process continues while new bubbles form around the wire until these bubbles are again swept away from the wire. This sweeping and reforming process appears to be the cause of large temperature fluctuations in the vertical case. It will be shown that synchronization accounts for the differences in the results between the horizontal and vertical orientation. 


\section{HEAT TRANSFER CHARACTERISTICS}

This investigation collects the temperature fluctuation data of a heater/thermometer. Steady-state power was applied to a platinum wire immersed in a liquid nitrogen at ambient pressure. Analysis of this data shows that the fluctuations about the average in the heat flux-temperature plane generally follow a counterclockwise trajectory. This behavior can be explained by considering the power balance equation.

When characterizing the heat transfer properties of a boiling liquid, a plot of the steady-state values of heat flux and superheat temperature is usually made. The two quantities of interest in this experiment were the time-dependent temperature and heat flux at the heater/liquid interface for a steady-state application of power to the heater. The heat flux per unit area $(\dot{q} / A)$ into the liquid was calculated from conservation of energy considerations as

$$
\dot{Q} \equiv \frac{\dot{q}}{A}=\frac{P}{A}-\frac{C}{A} \frac{d T}{d t}
$$

where $\dot{q}$ is the heat flow, $A$ is the surface area of the heater, $P$ is the applied power that is held nearly constant in these experiments, $C$ is the heat capacity of the platinum wire and $d T / d t$ is the time derivative of the temperature. 
Figure 2 shows a typical trajectory in the $\dot{Q}-\Delta T$ plane for moderate power inputs under nucleate boiling conditions. Note that the average superheat temperature and the average heat fluxes have been subtracted out from the data to emphasize the fluctuations. The arrowheads are drawn to indicate the direction of circulation. Peak to peak fluctuations in the temperature and the heat flux approach 1 kelvin and $1 \mathrm{~W} / \mathrm{cm}^{2}$, respectively. The average values and the range of the fluctuations depend on the applied power. The qualitative physical picture that is consistent with this direction of the circulation is as follows. The trajectory in the $\dot{Q}-\Delta T$ plane of the state of the system is described roughly by an ellipse. Individual nucleation sites undergo the following "life" cycle. In this microscopic point of view, the bubble detaches from the heater surface and rises through the liquid. A new thermal boundary layer starts to form as the surface heats up. At some later time, and at a high enough superheat, a bubble begins to grow at the site. As the bubble continues to grow the heat of vaporization is the dominant factor in cooling at the solid interface. When the bubble increases in size it begins to insulate the wire, thus diminishing cooling by means of conduction or convection. Thus the overall rate of cooling begins to decrease with eventual increase in the temperature. Finally, when the bubble becomes large enough, it breaks off and leaves the surface because of buoyant forces. The liquid then rushes in, thereby initiating the process again. Investigations involving single nucleation sites in water 


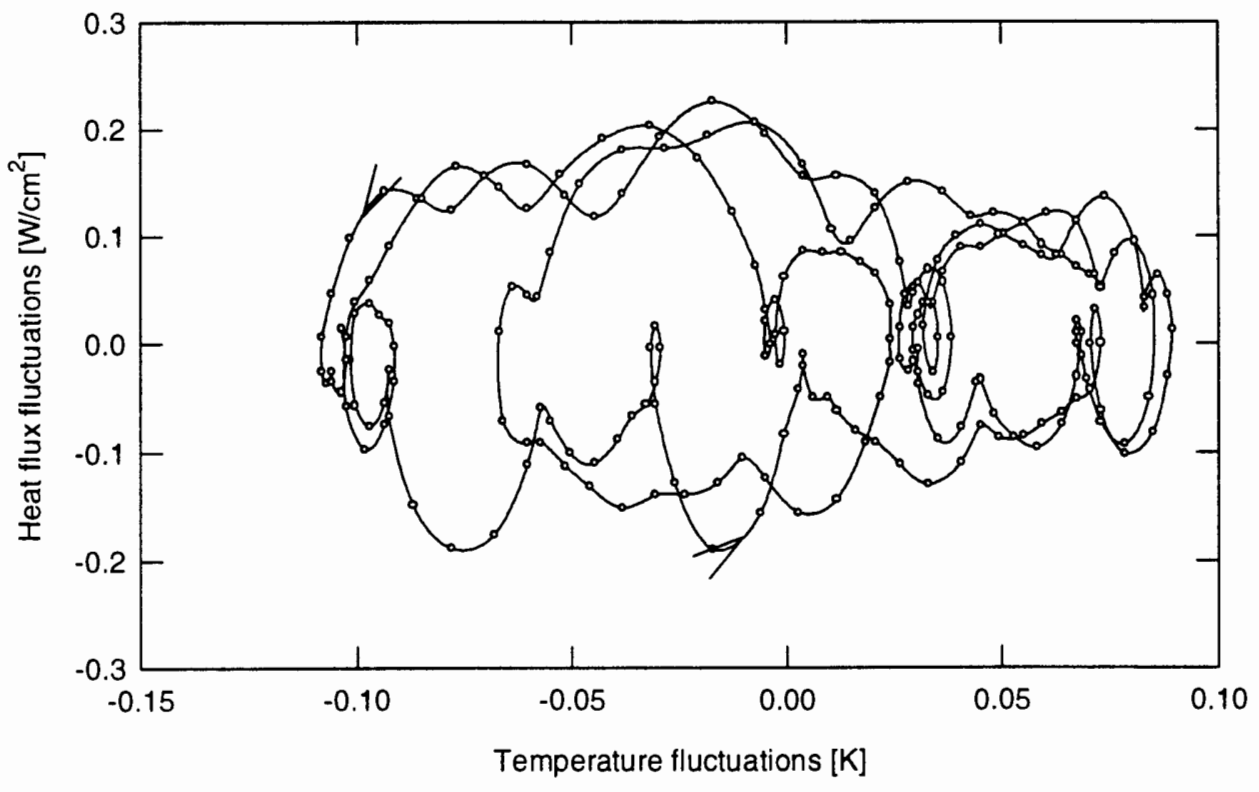

Figure 2. Fluctuations about the average in the temperature-heat flux plane. 
appear to concur with this description. ${ }^{6,7}$ 


\section{CHAPTER 2 EXPERIMENTAL SETUP}

\section{APPARATUS DESCRIPTION}

The apparatus constructed to carry out this investigation consisted of the wire support assembly, the support rod and the lift arm. The wire support assembly contains the platinum wire/heater and is the part of the equipment that can be rotated from a horizontal position (Figure 3) to a vertical position (Figure 3 inset). The diameter of the platinum wire is $0.102 \mathrm{~mm}$ and has an overall length of $7 \mathrm{~cm}$. The effective length (distance between voltage leads) is $3.16 \mathrm{~cm}$. The use of the platinum wire, as a resistance thermometer as well as a heater, minimizes errors when determining the heat flux and temperature when compared to a spatially separated thermometer and heater. The support rod is attached to the wire support 
assembly through a pivot point, allowing movement of the wire assembly. The rod is then used to lower the entire apparatus into the nitrogen bath and keep the current and voltage leads separated. The current leads between the support rod and the wire support assembly need to be flexible. We determined that wires with vinyl insulation were too rigid to allow for rotation of the wire assembly. Instead we used braided shielding that could conduct enough current and still remain flexible in liquid nitrogen. The lift arm was connected to the right end of the wire support assembly through another pivot point. It is used to change the orientation of the platinum wire without having to remove the apparatus from the nitrogen bath. This allowed us to compare temperature fluctuations from both orientations while changing the minimum amount of parameters in the experiment. Thin leads were soldered to the platinum wire for voltage measurements. The small voltage fluctuation data from the platinum wire, which corresponds to temperature fluctuations, were amplified using a differential amplifier with a DC offset. The signal was then routed to a HEM Data Corporation DAS-12 data acquisition board in a computer for data collection.

\section{DATA COLLECTION PROCEDURE}

Data collection involved first placing the wire support assembly in the vertical position. The entire apparatus was then carefully lowered into a liquid nitrogen 
storage container with the liquid at ambient pressure. A storage container was used instead of a dewar to accommodate the width of the wire support assembly while situated in the horizontal position. The only size constraint with the storage dewar was the diameter of the filler neck (approximately $6.4 \mathrm{~cm}$ ). The apparatus was constructed to fit through the filler neck while taking full advantage of the much larger diameter of the storage container's main body. The wire support assembly was then moved to the horizontal position and locked into place. A constant current was then set and recorded. The absolute voltage across the heater for this current is also recorded. The relative DC offset was adjusted so that the voltage fluctuations of the platinum wire would occur within the range of the data acquisition card. Voltage data were sampled over a 3 second time period, at 4000 samples per second, for a total of 12000 data points at that specific current level. The current level was then changed and the recording process was repeated. All the horizontal data were collected starting at the lowest current level and then adjusting the level upwards incrementally until transition to film boiling occurs. Next, the wire support assembly was moved to the vertical position and locked into place. The procedure used for acquiring vertical position data is identical to the procedure previously described for the horizontally positioned wire. 


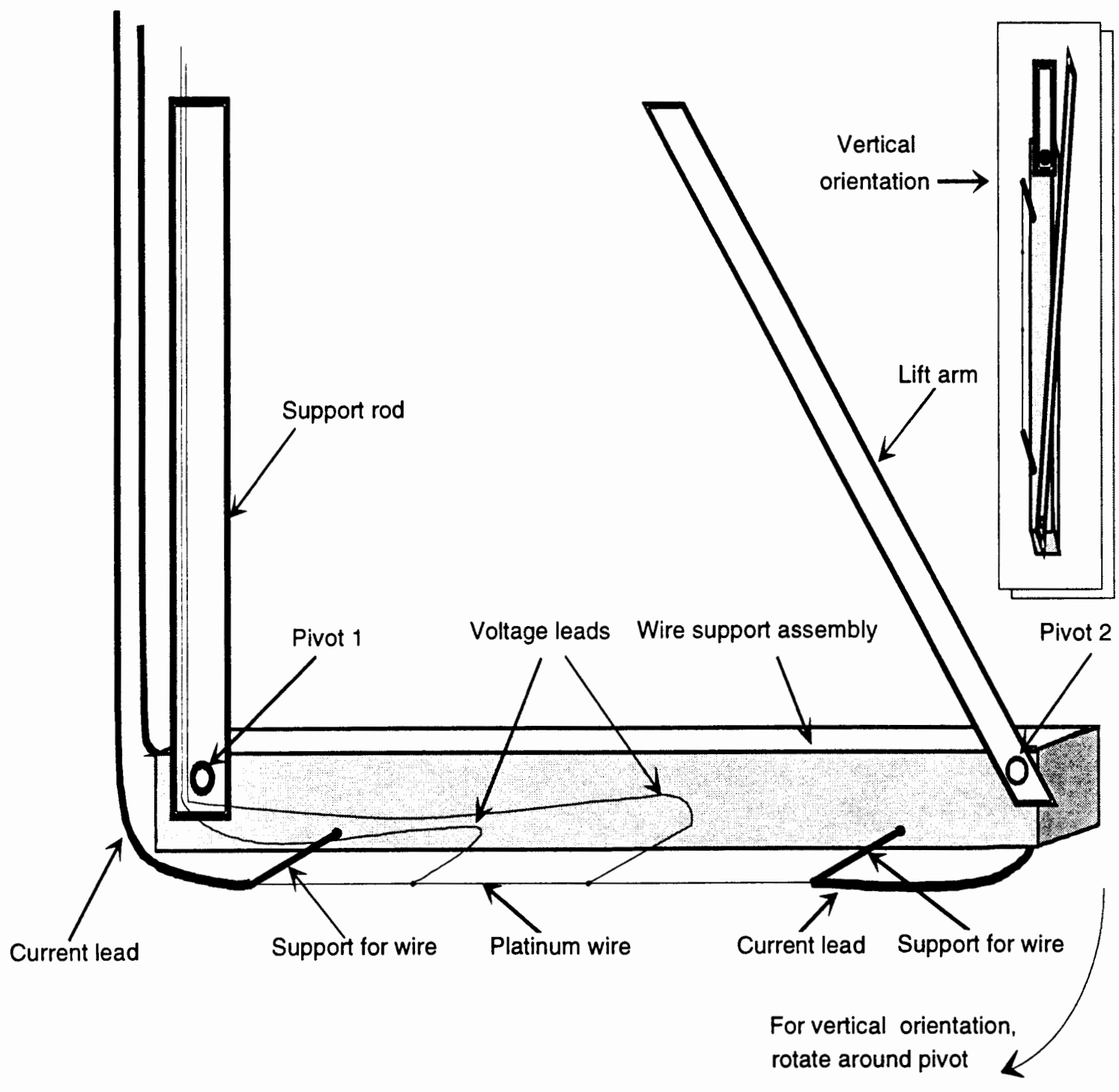

Figure 3. Experimental apparatus diagram with the platinum wire in the horizontal position. The inset shows the wire in the vertical position. 


\section{THERMAL TIME CONSTANT}

The thermal time constant of the platinum wire thermometer, $\tau$, is given by

$$
\tau=r^{2} \frac{\rho c}{k}
$$

where $r$ is the radius of the wire, $\rho$ is the density of the wire, $c$ is the specific heat of the wire and $k$ is the thermal conductivity of the wire. This is roughly the time for the interior and surface temperatures of the wire to equalize. For the platinum wire in this investigation, $\tau$ was determined to be $60 \mu$ s. Since our observed temperature fluctuations were much slower than $60 \mu$ s and the sampling time was $250 \mu \mathrm{s}$, it is assumed that the temperature everywhere in a cross-sectional area of the wire is uniform. Therefore, the response time of the platinum thermometer is deemed adequate to record the fastest temperature fluctuations (around $300 \mathrm{~Hz}$ ). However, it is not assumed that the temperature is necessarily constant between any two points along the length of the wire. The heating current was controlled by an op-amp/transistor assembly configured to produce the desired constant current. This amounted to nearly a constant applied power (within 1\%) since the overall resistance of the platinum wire changed insignificantly with the small temperature fluctuations in the experiments. 
TYPICAL DATA COLLECTION

A typical data run consisted of setting the constant current source to a predetermined value such that nucleate boiling could be observed. Measurements of the applied current and the voltage across the heater/thermometer were performed by the data acquisition system installed in our laboratory computer. Values of the resistance and therefore of the temperature of the heater/thermometer were then digitally computed. This process was then repeated for increasing current levels until the transition from nucleate boiling to film boiling occurred. The time dependent heat flux was then calculated for each current level and used in the data analysis in chapter 3. 


\section{CHAPTER 3 RESULTS AND DISCUSSION}

\section{RAWDATA ANALYSIS}

Figure 4 is a graph of horizontal wire voltage data with the mean value of the data set subtracted from each data point. This was done to more easily compare horizontal and vertical data visually. The graph has 4000 data points. Since the sample rate is 4000 samples per second, the graph shows a one second data sample. Each data point represents the relative voltage across the platinum wire every 250 microseconds. A moderately high current level was selected $(2.7 \mathrm{~A})$ to graph the horizontal and vertical differences. For this current level, both orientations exhibit nucleate boiling characteristics.

Figure 5 is a graph of vertical wire data. It, like Figure 4, has 4000 voltage samples. The same current level as in Figure 4 was graphed $(2.7 \mathrm{~A})$. Note the amplitude of the fluctuations and compare with the fluctuations in Figure 4. The y- 
axis scale for both graphs is the same. The magnitude of the vertical fluctuations is significantly larger than in the horizontal case. For any moderate or high current level, the vertical voltage fluctuations are always larger than the horizontal fluctuations.

Figure 6 is a comparision of voltage fluctuations across the platinum wire at $2.7 \mathrm{~A}$. 200 samples for each orientation gives the entire time for the graph as 50 miliseconds. Again, fluctuations are much larger in the vertical case.

\section{PLATINUM WIRE RESISTANCE}

Figure 7 is a plot of resistance versus current. Transision of the heat transfer process from convection to nucleate boiling is shown by the sharp drop in resistance. Note that the vertically orientated wire undergoes transistion at a lower current level. Also note that for low current levels, the resistance for both orientations is nearly identical. Synchronization is not a significant process at these lower levels.

\section{FAST FOURIER TRANSFORMATIONS}

Figure 8 is a Fast Fourier Transformation (FFT) of the same raw vertical data as in Figure 5. The FFT used 4096 data points for the calculations. Only left peak of the FFT is shown since the remainder does not show any features. The D.C. level also was not graphed. The real and imaginary FFT parts were combined to produce this 
graph. The graph indicates a $1 / \mathrm{f}$ structure at low frequencies and a white noise spectrum at high frequencies. The white noise is due to the limited resolution of the electronics used in this experiment. The $1 / \mathrm{f}$ spectrum indicates either a random or chaotic signal.

Figure 9 is a Fast Fourier Transformation of the same raw horizontal data as in Figure 4. Again, 4096 points are used for calculating the FFT. The 1/f structure is also evident here. Note the difference in amplitude when compared with Figure 8. The overall FFT amplitude is greater with the vertical orientation.

\section{CIRCULATION ANALYSIS}

The final analysis of the experimental data for a run is shown in Figure 10 and Figure 11. It shows the area associated with the two orientations of the same wire. The temperature fluctuations were analyzed by calculating the area swept out in unit time by the counterclockwise closed circulation in the heat flux-superheat temperature $\dot{Q}-\Delta T$ plane. The error bars were calculated by partitioning the data set at each current level into four parts and calculating the area and the standard deviation of the resulting sets. The area was calculated using the computer program listed in appendix B. All the data reported in Figure 10 were obtained by first performing the measurements at all the selected current levels in the horizontal orientation and then switching to the vertical position. Similar results were obtained by taking the 
measurements in both orientations at every selected current. The vertical data are similar to previous observations. ${ }^{4,5}$ It is seen that, again, upon approaching the critical heat flux in the vertical orientation, $\left(\mathrm{CHF}\right.$, approximately $\left.9.5 \mathrm{~W} / \mathrm{cm}^{2}\right)$ the area seems to level out. As was done previously, the curve through the vertical data represents a quartic fit, which seemed to adequately follow the experimental points.

\section{DATA ANALYSIS COMPARISIONS}

Comparing the data for the horizontal orientation with the vertical position, several significant differences are observed. First, the CHF is higher (about $11 \mathrm{~W} / \mathrm{cm}^{2}$ ) for the horizontal orientation. ${ }^{8}$ This can be explained by the fact that rising bubbles interfere with the efficient heat transfer in the vertical case and, in fact, limit the maximum heat flux that the vertical wire can support.

Second, Figure 10 shows a factor of three difference in the area between the two orientations. It should be pointed out that the only difference between the two data sets is the orientation. The wire is the same; it has the same nucleation sites, the same boiling sites, and the same imperfections. So the observed differences are due solely to the effect of the horizontal or vertical geometry. This can be understood by referring to the model for the generation of the area. In the vertical case different nucleation sites tend to be synchronized because of the feedback provided by the 


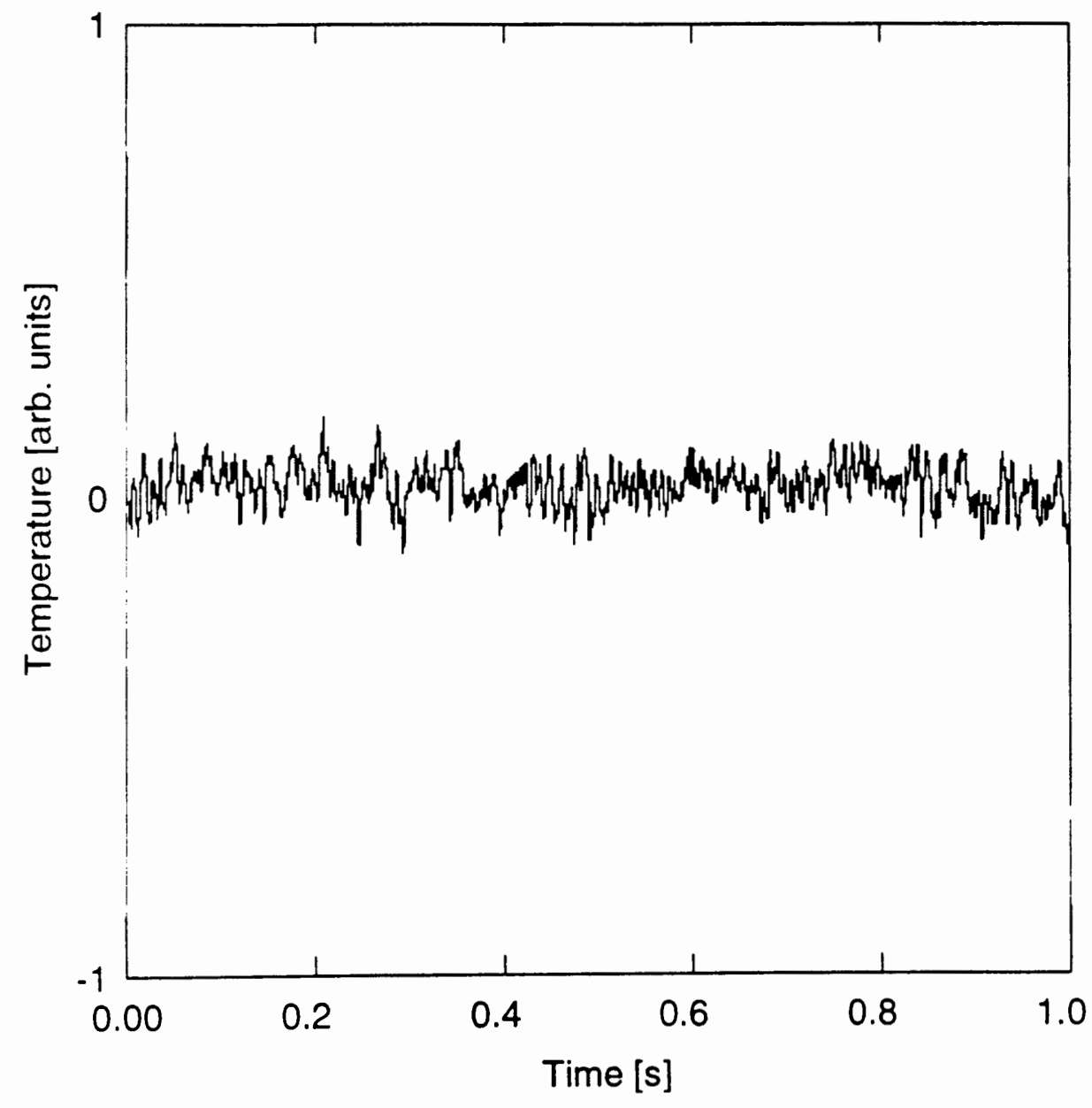

Figure 4. One second temperature data with the wire in a horizontal orientation. 


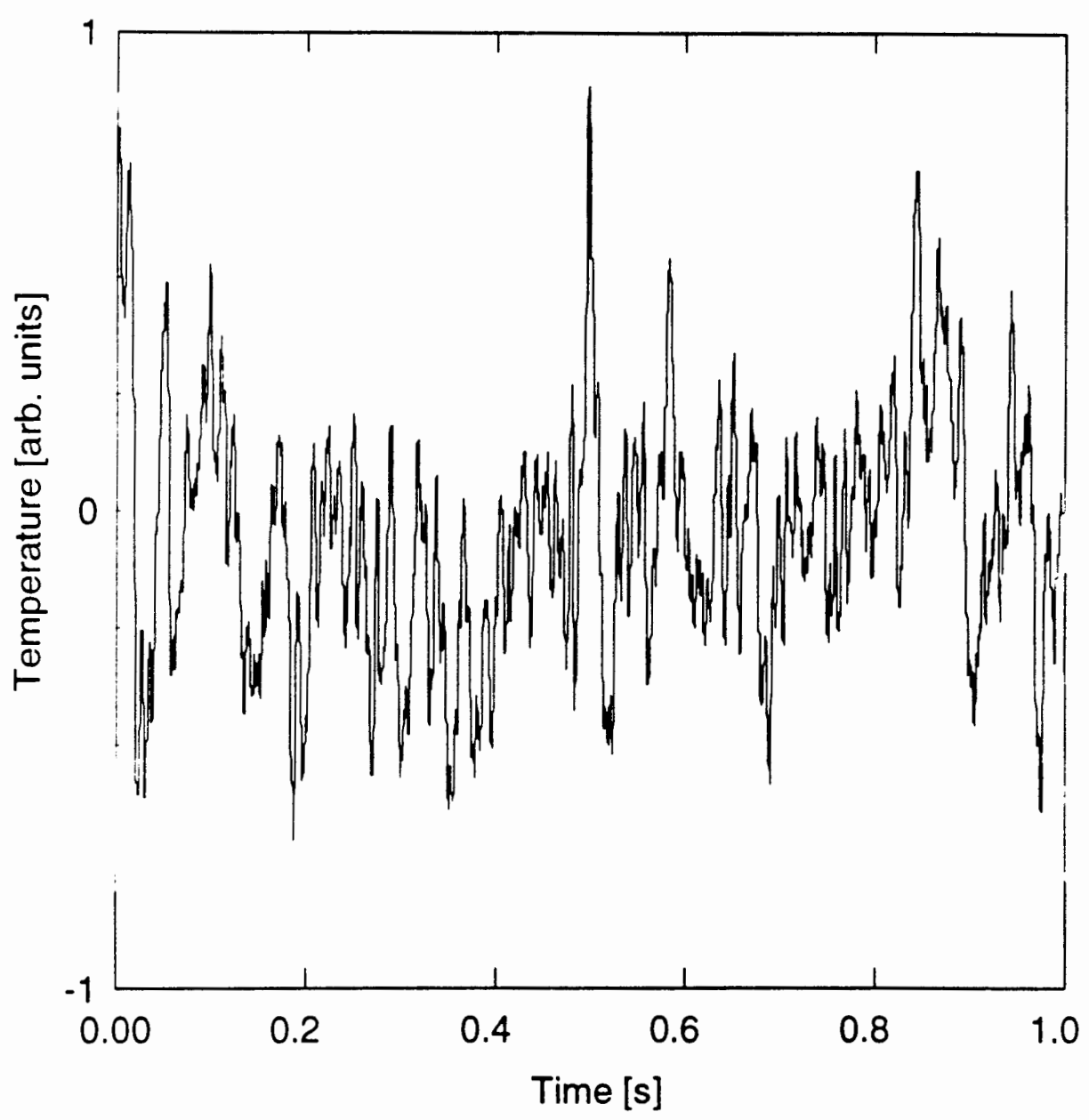

Figure 5. One second temperature data with the wire in a vertical orientation. Temperature scale is the same as for Figure 4. 


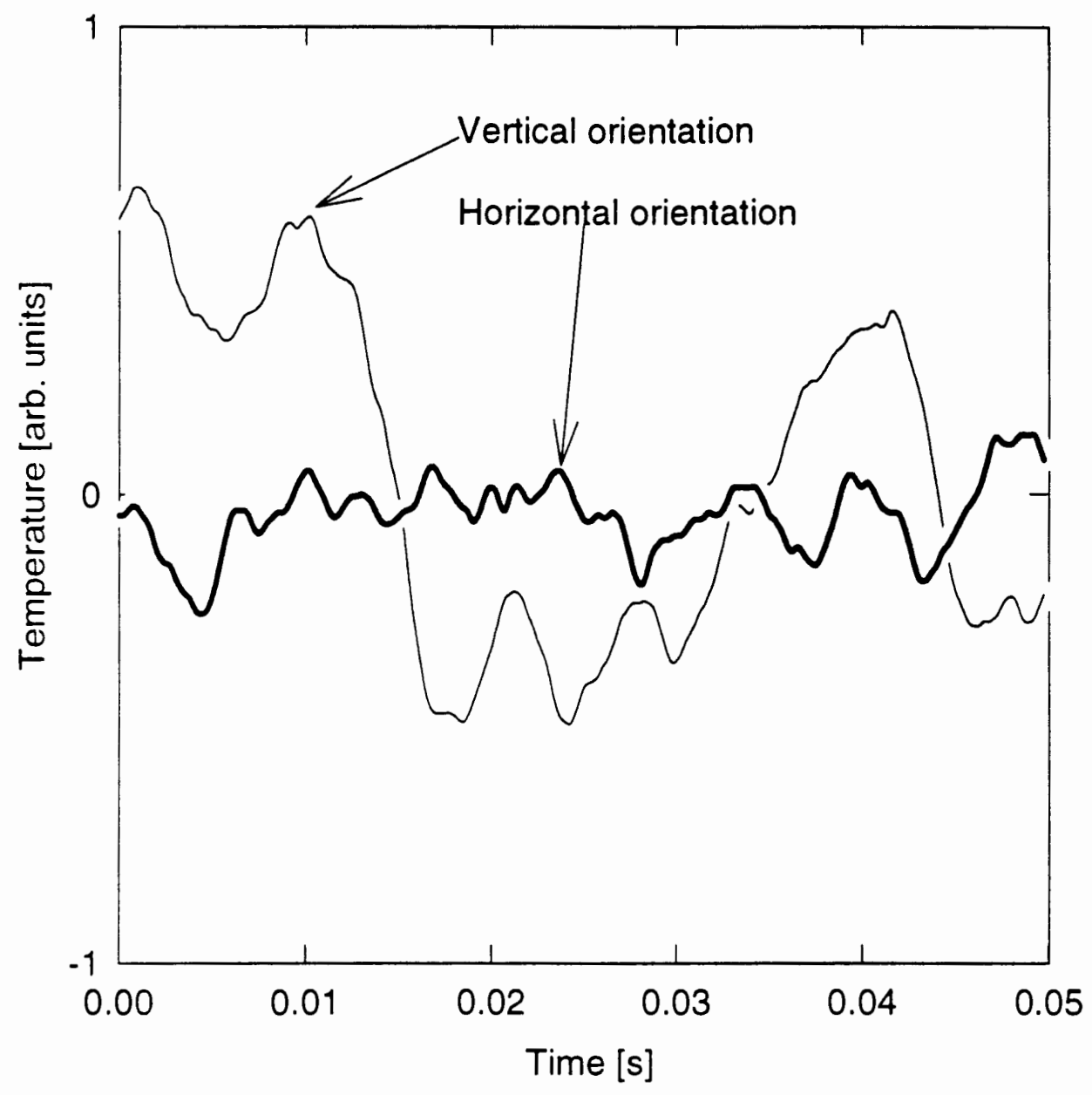

Figure 6. Comparision of the temperature across the platinum wire using the same current level but different orientations. 


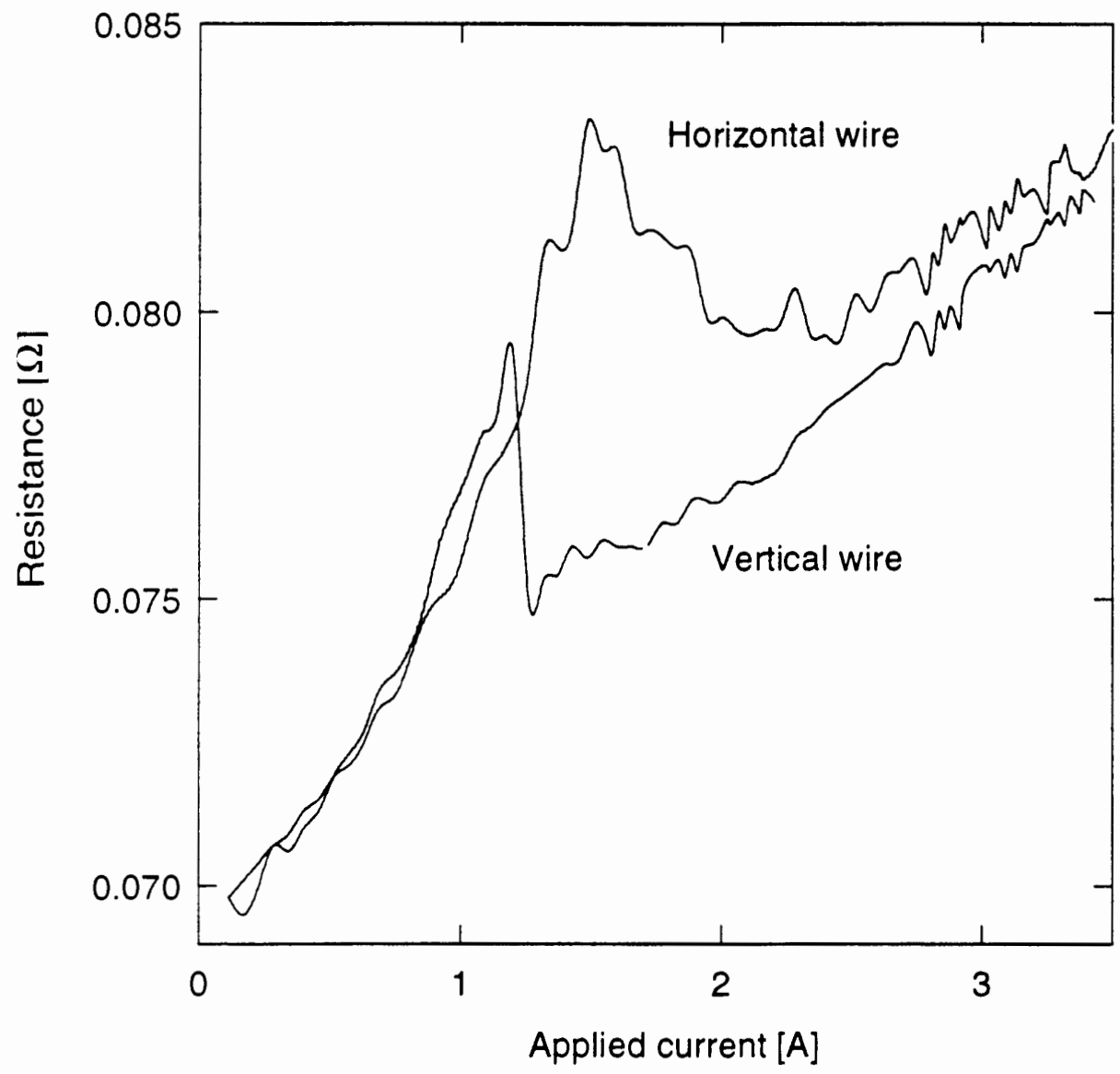

Figure 7. Plot of the platinum wire resistance versus applied current. 


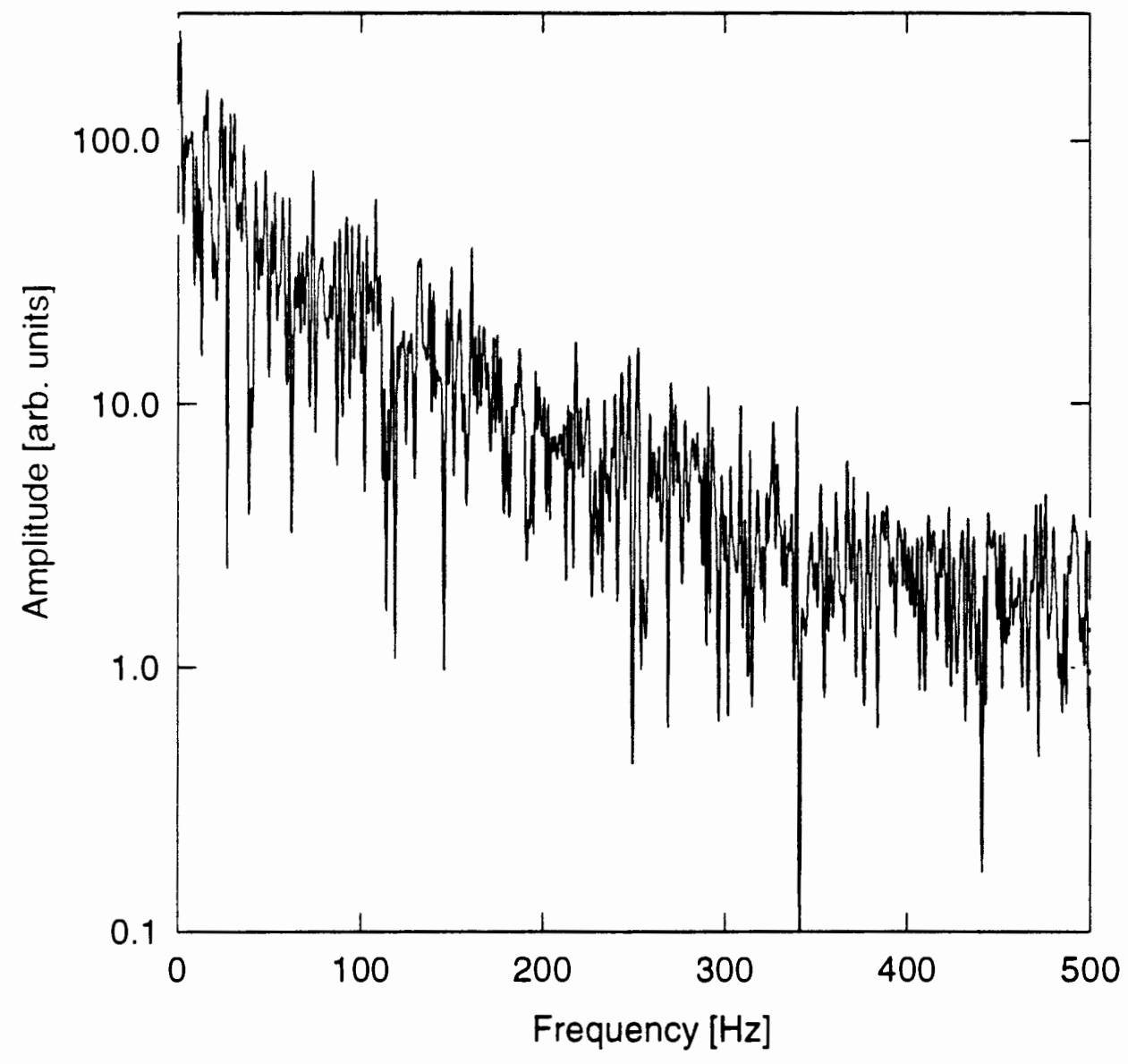

Figure 8. 4096 point Fourier Transform of the vertical data at 2.7 A. 


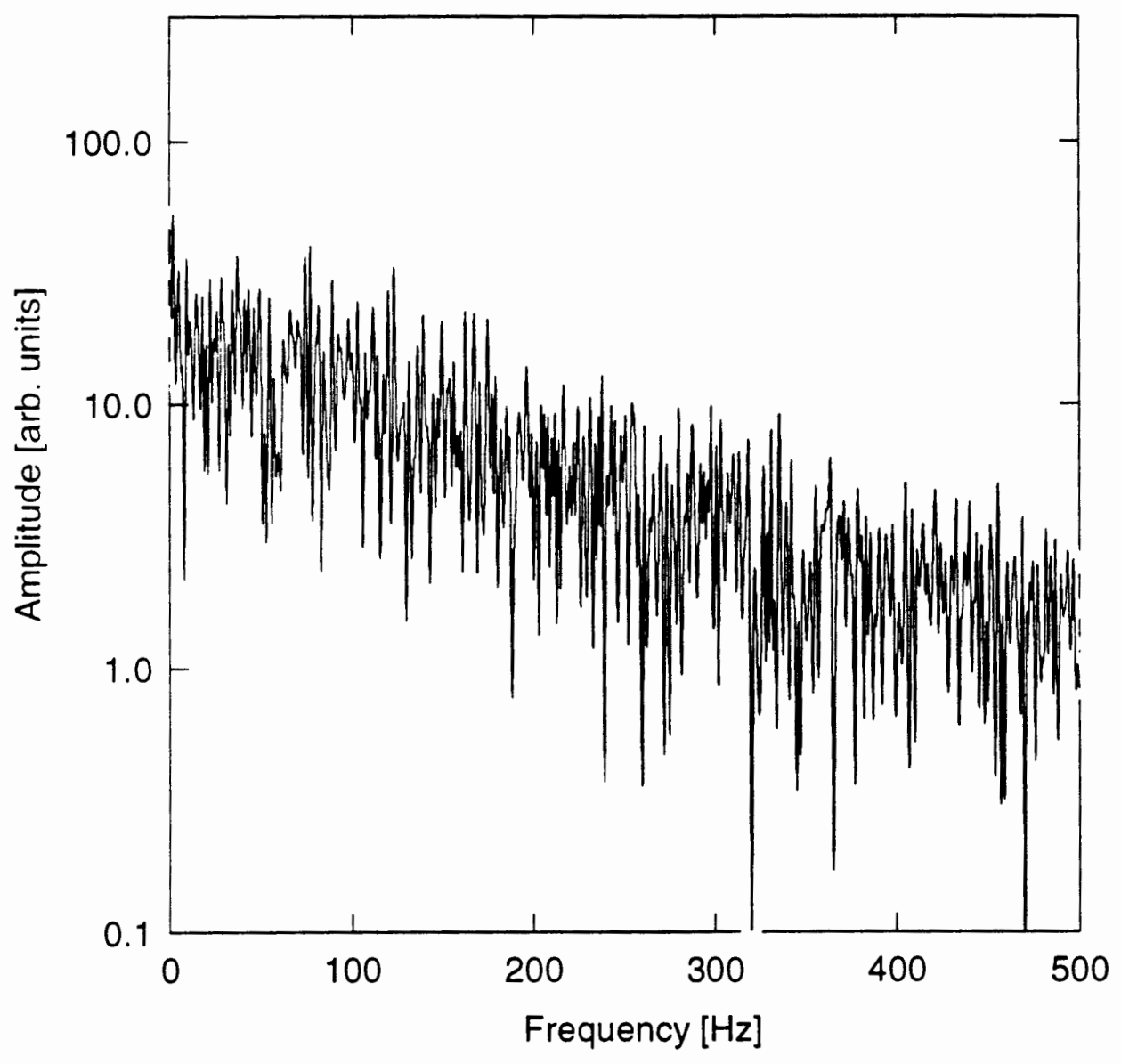

Figure 9. 4096 point Fourier Transform of the horizontal data at 2.7 A. 


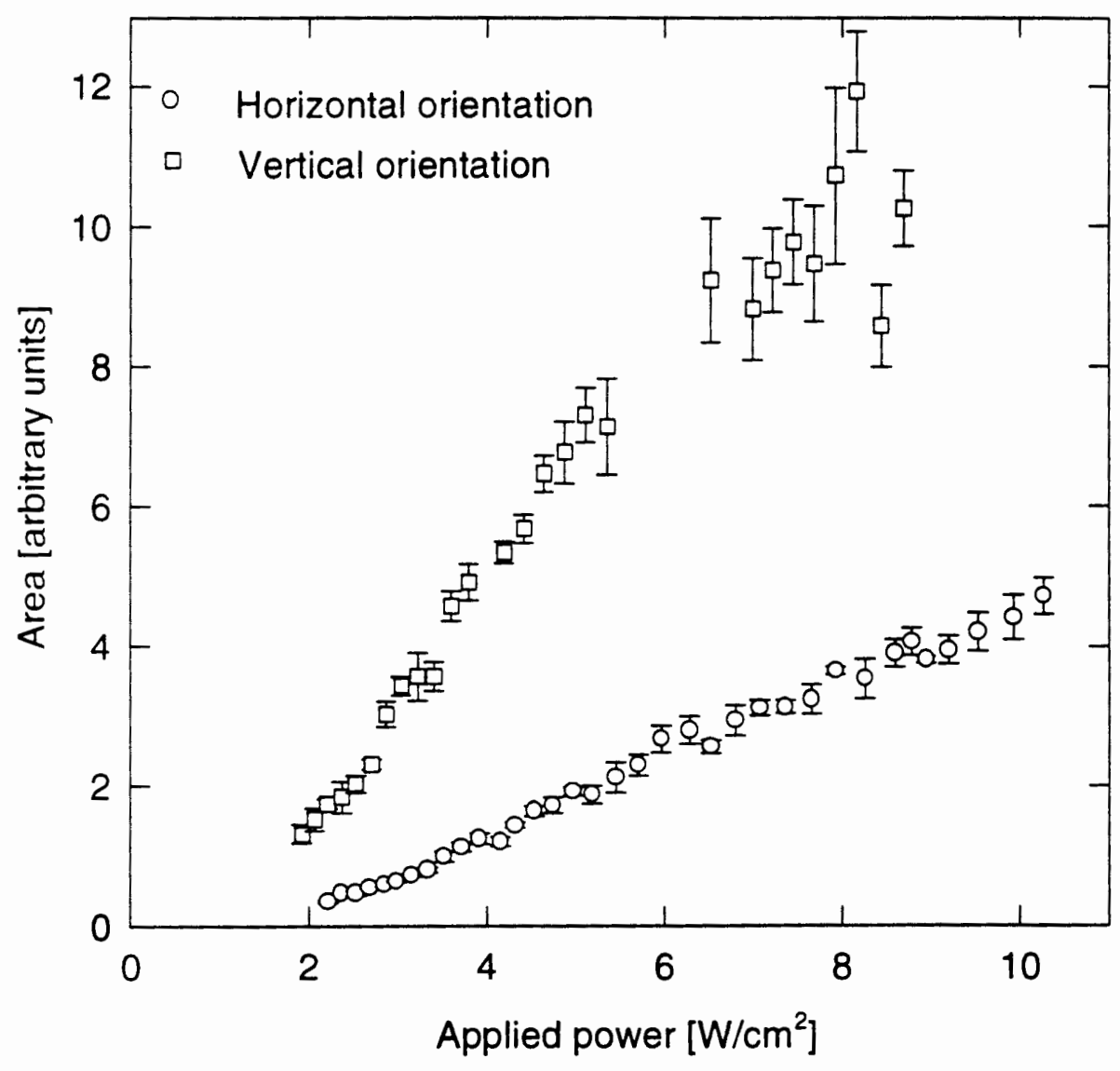

Figure 10. Circulation in the heat flux-temperature plane vs. the applied power. 


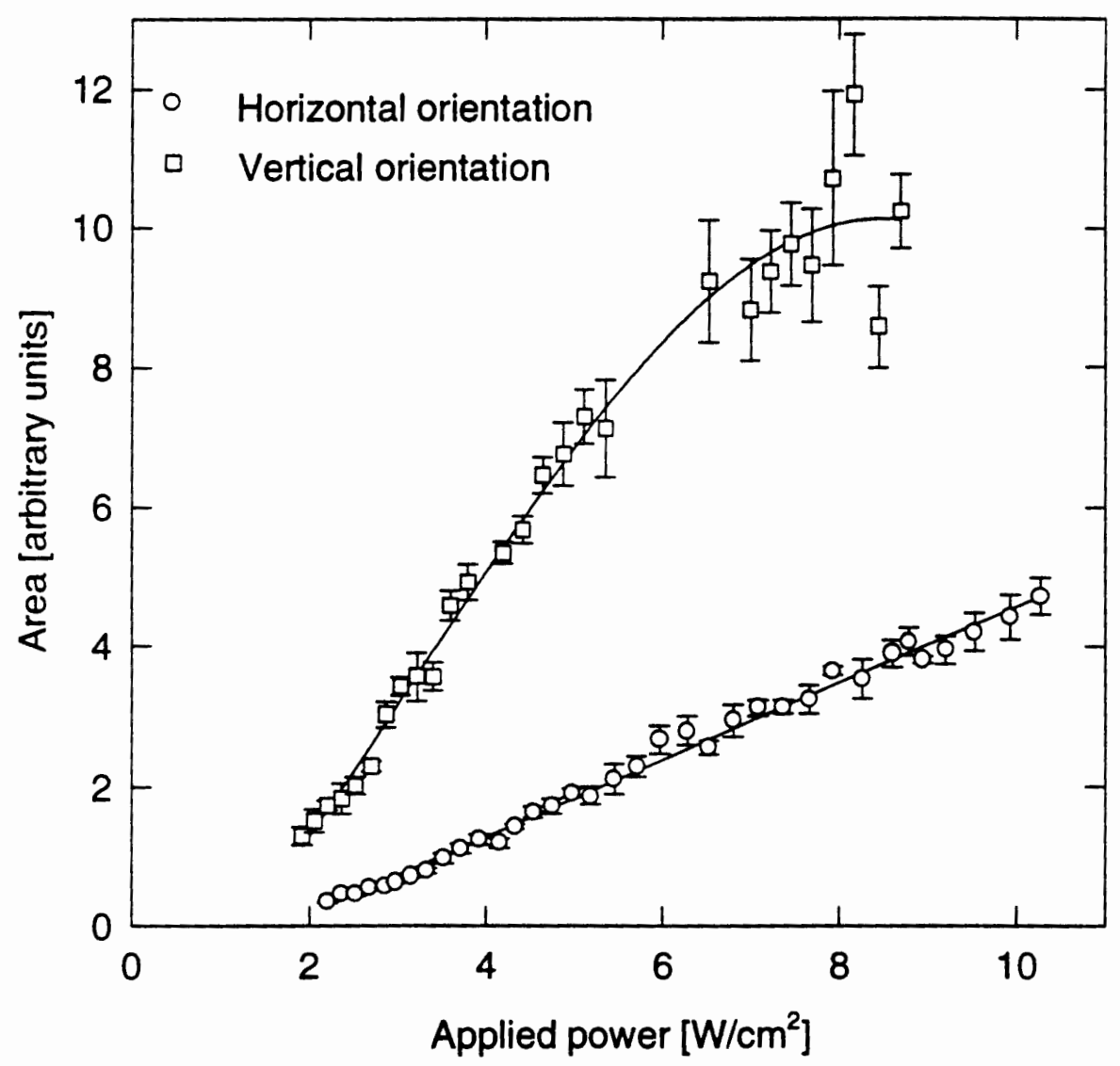

Figure 11. Circulation in the heat flux-temperature plane vs. the applied power with a quartic curve fit line added. 
bubbles rising past the vertical wire. Thus the average temperature of the wire between the potential leads, all other things being equal, will tend to undergo larger fluctuations and the associated area will also be larger. Although, in the horizontal case adjacent nucleation sites tend to be somewhat synchronized, this synchronization is much more pronounced in the vertical case. So, for the first time, these measurements provide direct support for the proposed model. ${ }^{4,5}$

Third, the data for the horizontal orientation are well represented over the total range by a linear regression, in contrast to the vertical orientation where above about $7 \mathrm{~W} / \mathrm{cm}^{2}$ the relationship ceases to be linear. The linear relationship between area and the applied power can be understood based on the fact that the area is proportional not only to amplitude of the temperature fluctuations but also to the frequency of these fluctuations. The simplest way to see this is that frequency is related to the time for a bubble to grow to a size at which it detaches from the wire. This time is roughly inversely proportional to the applied power and thus the frequency increases linearly with the applied power. On the other hand, the magnitude of the temperature fluctuations is approximately constant because it is determined by the maximum size of the bubble and by the influx of the cold liquid. Thus, since the area is roughly equal to the product of this magnitude and the frequency, area is linear with applied power. In the vertical case, around 7 to $9 \mathrm{~W} / \mathrm{cm}^{2}$ the linear relationship between area and the applied power is lost because the rate of release of bubbles is so large that the synchronization decreases in significance. If somehow film boiling could be 
prevented, one would expect that at large applied powers, the area would drop down to the area for the horizontal wire. This loss of synchronization occurs over a certain range of applied powers, resulting in the generation of a broad peak. The data in this region is subject to perturbations extrinsic to the experiment per se (e.g., release of bubbles from the support structure, convective flow in $\mathrm{LN}_{2}$, etc.). These perturbations have a large effect, as can be observed from the error bars in Figure 10 and Figure 11. 


\section{CHAPTER 4 CONCLUSIONS}

This work has shown that for steady-state nucleate boiling in liquid nitrogen, the temperature fluctuations of the heater wire depend upon its orientation (vertical or horizontal). The temperature fluctuations were analyzed by calculating the area swept out in unit time by the counterclockwise closed circulation in the heat flux-superheat temperature $\dot{Q}-\Delta T$ plane.

When plotted as a function of the applied heater power, the $\dot{Q}-\Delta T$ area for the horizontal wire differs in three main respects from that for the vertical wire. The two most significant differences are shown in Figure 10. The peak that appears so clearly in the 6 to 9 watts $/ \mathrm{cm}^{2}$ region for the vertical wire is completely absent in 
the case of the horizontal wire. The $\dot{Q}-\Delta T$ area for the horizontal wire is only about $1 / 3$ that of the vertical wire at any particular heater power. In addition, it was found that the critical heat flux was less for the vertical wire.

It is probable that the two differences evident in Figure 9 arise from the same basic reason. Previously, ${ }^{4,5}$ it was pointed out that there are probably many active nucleation sites on the heater wire surface between the potential leads. Therefore, one would not expect the counterclockwise circulation in the $\dot{Q}-\Delta T$ plane, which exists at any one nucleation site, to be manifest in our data unless there is a cooperative phenomenon occurring that tends to synchronize the activity at the various sites. The work reported here supports this idea. Since the bubbles leaving each site rise vertically through the liquid, they will have a much greater synchronizing effect for the vertical wire than for the horizontal wire. However, even for the vertical wire the synchronizing effect of the rising bubbles will tend to decrease as the applied heating power is increased because the frequency of bubble detachment increases. The maximum in the $\dot{Q}-\Delta T$ area vs. applied power for the vertical orientation is the result.

The above discussion suggests further studies. For the vertical wire, the extent of the synchronization can be determined by measuring the area $\dot{Q}-\Delta T$ for wires of increasing length. Such measurements might provide additional information on the speculation mentioned previously, that the peak might serve as a predictor of the 
transition from nucleate to film boiling. The possibility of generalizing the use of the area as a predictor in other configurations where cooperative phenomena are present is still an open question.

Other possibilities for future studies are suggested by this work. For example, by taking measurements on heating wires oriented at angles between the horizontal and vertical, it could be determined whether the transition between the horizontal and vertical heating wire is smooth or whether there is some intermediate orientation for which the cooperative phenomenon is a maximum. Also, it would be worthwhile to investigate the possibility of reducing the scatter in the higher power region of Figure 10 by increasing the sampling times. Finally, it is tempting to speculate on the further applicability of the techniques in chaos theory to the analysis of the temperature fluctuations. 


\section{REFERENCES}

1. D.N. Sinha, L.C. Brodie, J.S. Semura, and F.M. Young, Premature transition to stable film boiling initiated by power transients in liquid nitrogen, Cryogenics 19:225 (1979)

2. E.W. Roth, E. Bodegom, L.C. Brodie, and J.S. Semura, Suppression of the premature transition to film boiling in LN2 using forced convection in: Advances in Cryogenic Engineering, Vol. 37A, (1991), p. 197

3. M. Shiotsu K. Hata and A. Sakurai, Heterogeneous spontaneous nucleation temperature on solid surface in liquid nitrogen, in: Advances in Cryogenic Engineering, Vol. 35A, (1990) p.437

4. E.W Roth, Nucleation and heat transfer in liquid nitrogen, Ph.D. Dissertation, Portland State University, Portland, OR (1993)

5. E. W. Roth, J.S. Semura, L.C. Brodie, and E. Bodegom, Novel approach to the analysis of fluctuations in steady-state nucleate boiling, in: Advances in Cryogenic Engineering, Vol. 39, (1994), p. 1741 
6. S.T. Hsu and F.W. Schmidt, Measured variations in local surface temperatures in pool boiling of water, J. Heat Transfer, Trans. ASME, (August 1961) p. 254

7. Thomas F. Rogers and Russel B. Mesler, An experimental study of surface cooling by bubbles during nucleate boiling of water, A.I.Ch.E. Journal, (September 1964) p. 656

8. C. Beduz, R.G. Scurlock, and A.J. Sousa, Angular dependence of boiling heat transfer mechanisms in liquid nitrogen, , in: Advances in Cryogenic Engineering, Vol. 33, (1988), p. 363 


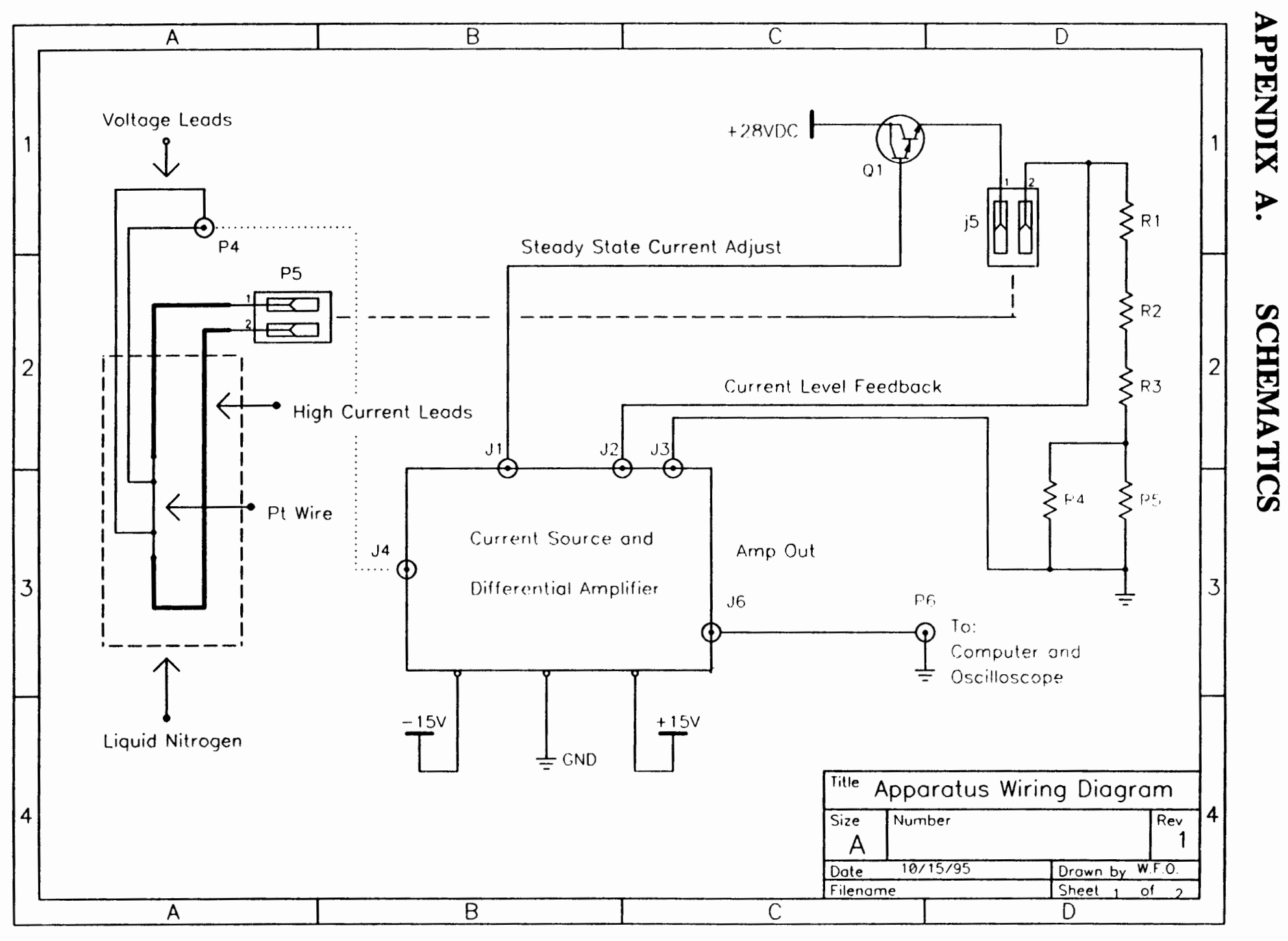




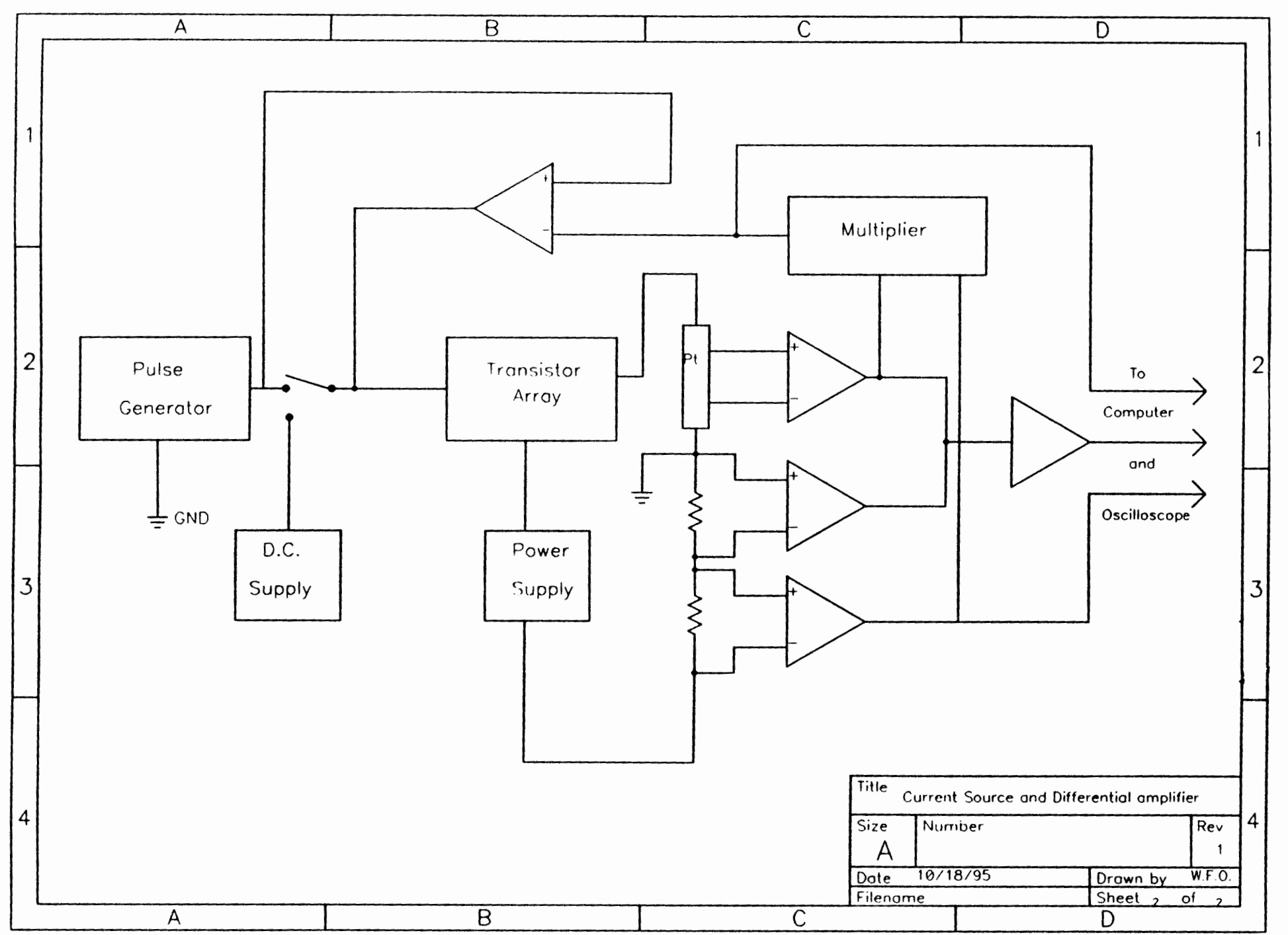

un 
Q1 NTE 249 NPN Darlington Transistor

R1 $0.25 \mathrm{Ohm} 100$ Watt Resistor

R2 $0.25 \mathrm{Ohm} 100$ Watt Resistor

R3 $\quad 0.25 \mathrm{Ohm} 100$ Watt Resistor

R4 $\quad 0.25 \mathrm{Ohm} 100$ Watt Resistor

R5 $0.25 \mathrm{Ohm} 100$ Watt Resistor

J1-J6 BNC Jacks

P1-P6 BNC Connectors

All Cables are Shielded Coaxial. 


\section{APPENDIX B COMPUTER PROGRAM TO CALCULATE CIRCULATION}

program QTplot;

\{modified 6/28/95 take out plotting,take sets of data(3000)at a time

modified $7 / 7 / 95$ to deal with new data set....

also fixed factors for area....

\}

uses Dos,Crt,Graph,Graphprn,Printer2;

const

Ndata $=3000\{100\} ;\{$ Number of data to be evaluated $\}$

type

Data $=\operatorname{array}[1 .$. Ndata $]$ of integer; $\{$ Array for storing raw data $\}$

$\mathrm{QT}=\operatorname{array}[1 . . \mathrm{Ndata}]$ of real; $\{$ Array for storing calculated temp an $\mathrm{Q}$ data $\}$

datatype $=\operatorname{array}[1 . .75]$ of real;

var

hc,hv,vc,vv:datatype;

R : Data; 
$\mathrm{T}, \mathrm{Q}:^{\wedge} \mathrm{QT}$;

i,yy,zz,ii,k,del,N,j : word;

ymin,ymax,xmax,Apos,Aneg,Anet : real \{word\};

resist,minT,maxT:real;

avg:real;

$\mathrm{x}, \mathrm{y}$ : longint;

xzero,yzero : real;

Fname : string[40];

s2 : string[7];

s3 : string[1];

s4 : string[30];

$\min Q, \max Q$, Sample,Power,current,xscale,yscale : real ;

$\mathrm{t} 1, \mathrm{t} 2, \mathrm{t} 3, \mathrm{t} 4:$ word;

ch : char;

fvarl,fvar :text;

temp,temp 2 : word;

procedure INIT;

var

n1,n2,rmin,rmax,gd,gm,xa,xb,ya,yb:integer;

Ravrg :longint; 


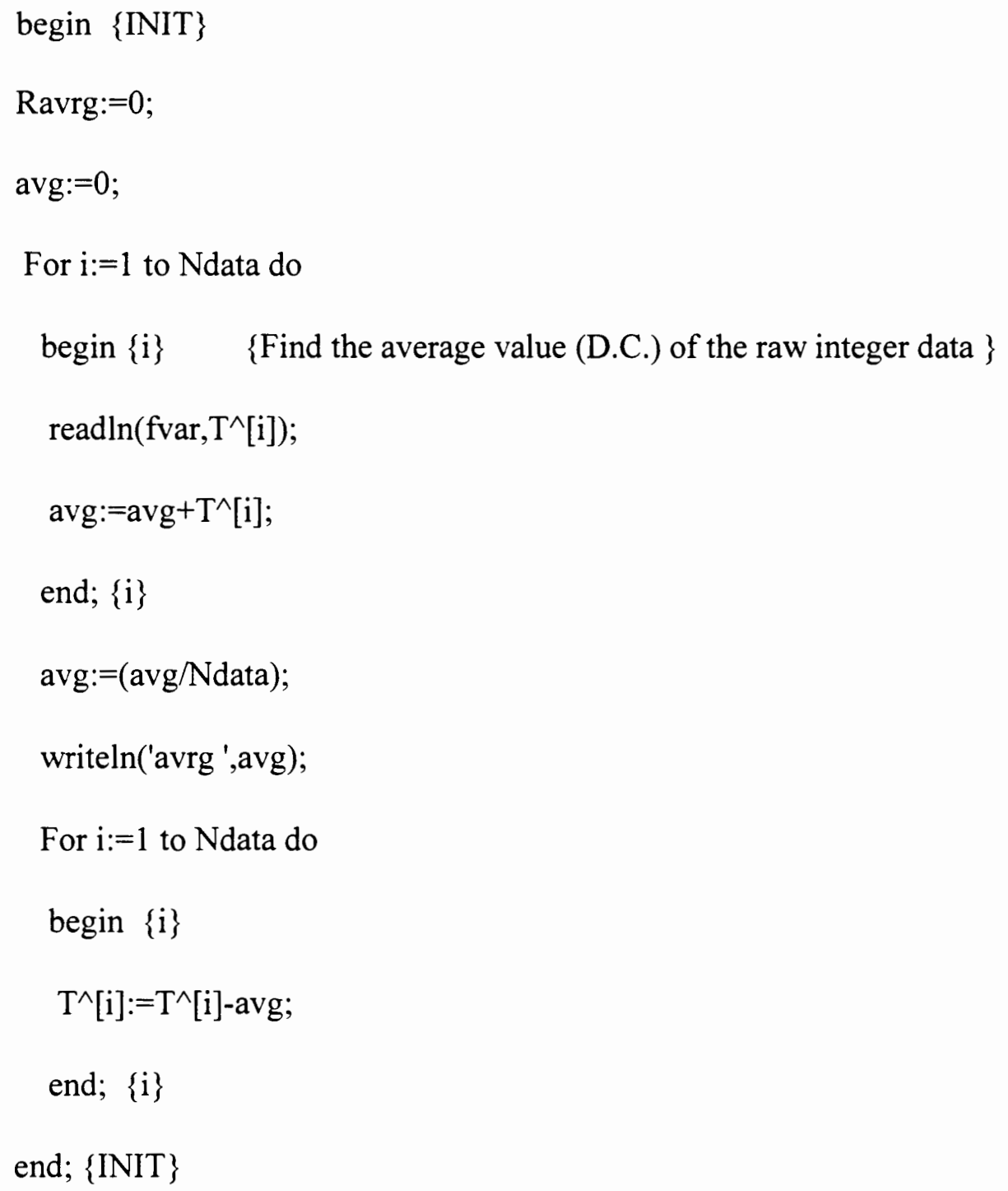

Procedure Temperature; \{Calculates temperature fluctuations about the var $\quad\{$ average temp.(not the superheat temp.)\} $\mathrm{k}$ : integer; $\quad$ \{from the voltage and current measurements\} dTmax,dTmin : real; $\quad$ assumes raw data already divided by 16 \} begin $\{$ Temperature $\}$ 
$\min T:=10000$

$\max T:=-10000 ;$

For $\mathrm{k}:=1$ to Ndata do

begin $\{k\}$

$\mathrm{T}^{\wedge}[\mathrm{k}]:=\mathrm{T}^{\wedge}[\mathrm{k}] / 1.25248 /$ current;

if $T^{\wedge}[\mathrm{i}]>\max T$ then $\max T:=T^{\wedge}[\mathrm{i}]$;

if $\mathrm{T}^{\wedge}[\mathrm{i}]<\min \mathrm{T}$ then $\min \mathrm{T}:=\mathrm{T}^{\wedge}[\mathrm{i}]$

end; $\{k\}$

end; $\{$ Temperature $\}$

Procedure Flux; $\quad$ Calculates the heat flux by $\mathrm{Q}=(\mathrm{P}-\mathrm{CdT} / \mathrm{dt}) / \mathrm{A}$ \}

var $\quad$ in $\mathrm{W} / \mathrm{cm}^{\wedge} 2$. Then will take FFT of Q\}

Capacity: real;

begin $\{$ FLUX $\}$

$\min Q:=10.0$

$\operatorname{maxQ}:=0.0 ; \quad\{$ Capacity: $=4.68 \mathrm{E}-3$; heat capacity

For $\mathrm{i}:=1$ to (Ndata-1) do

begin $\{i\}$

$\mathrm{Q}^{\wedge}[\mathrm{i}]:=\operatorname{Power}^{*}\left(0.0212^{*} \mathrm{~T}^{\wedge}[\mathrm{i}]\right)-$ sample${ }^{*} 4.68^{*}\left(\mathrm{~T}^{\wedge}[\mathrm{i}+1]-\mathrm{T}^{\wedge}[\mathrm{i}]\right)$;

$\left({ }^{*} \mathrm{Q}^{\wedge}[\mathrm{i}]:=\right.$ Power* $\left(0.0192 / 4^{*}\left(\mathrm{~T}^{\wedge}[\mathrm{i}-1]+2^{*} \mathrm{~T}^{\wedge}[\mathrm{i}]+\mathrm{T}^{\wedge}[\mathrm{i}+1]\right)\right)$ 
-sample*4.68/2* $\left.\left(\mathrm{T}^{\wedge}[\mathrm{i}+1]-\mathrm{T}^{\wedge}[\mathrm{i}-1]\right) ;{ }^{*}\right)$

if $\mathrm{Q}^{\wedge}[\mathrm{i}]>\max Q$ then $\max Q:=\mathrm{Q}^{\wedge}[\mathrm{i}]$;

if $\mathrm{Q}^{\wedge}[\mathrm{i}]<\min \mathrm{Q}$ then $\min \mathrm{Q}:=\mathrm{Q}^{\wedge}[\mathrm{i}]$;

end; $\{i\}$

end; $\{$ FLUX $\}$

Procedure Area;

begin $\{$ Area $\}$

Apos: $=0$;

Aneg: $=0$;

$T^{\wedge}[$ Ndata- 1$]:=T^{\wedge}[1]$

$\mathrm{Q}^{\wedge}\left[\right.$ Ndata-1]:= $\mathrm{Q}^{\wedge}[1]$

For $i:=1$ to (Ndata-2) do

begin $\{i\}$

$$
\text { Apos: }=A p o s+\left(T^{\wedge}[\mathrm{i}]-\mathrm{T}^{\wedge}[\mathrm{i}+1]\right)^{*}\left(\mathrm{Q}^{\wedge}[\mathrm{i}+1]+\mathrm{Q}^{\wedge}[\mathrm{i}]\right)
$$

end;

Anet:=Apos - Aneg;

writeln('Area ',Anet);

end; $\{$ Area $\}$

Begin \{Main Program\} 


$$
\begin{aligned}
& \mathrm{hc}[1]:=0.099 ; \quad \mathrm{hv}[1]:=0.0079 \text {; } \\
& \mathrm{hc}[2]:=0.151 ; \quad \mathrm{hv}[2]:=0.0121 \text {; } \\
& \mathrm{hc}[3]:=0.2 ; \quad \operatorname{hv}[3]:=0.0161 \text {; } \\
& \mathrm{hc}[4]:=0.25 ; \quad \mathrm{hv}[4]:=0.0201 ; \\
& \mathrm{hc}[5]:=0.3 ; \quad \mathrm{hv}[5]:=0.0243 \text {; } \\
& \mathrm{hc}[6]:=0.35 ; \quad \mathrm{hv}[6]:=0.0285 \text {; } \\
& \mathrm{hc}[7]:=0.4 ; \quad \operatorname{hv}[7]:=0.0327 \text {; } \\
& \mathrm{hc}[8]:=0.45 ; \quad \mathrm{hv}[8]:=0.037 \text {; } \\
& \mathrm{hc}[9]:=0.5 ; \quad \mathrm{hv}[9]:=0.0412 \text {; } \\
& h c[10]:=0.55 ; \quad h v[10]:=0.0456 ; \\
& \mathrm{hc}[11]:=0.6 ; \quad \mathrm{hv}[11]:=0.0501 \text {; } \\
& \mathrm{hc}[12]:=0.651 ; \quad \mathrm{hv}[12]:=0.0545 ; \\
& \mathrm{hc}[13]:=0.7 ; \quad \mathrm{hv}[13]:=0.0591 \text {; } \\
& \text { hc[14]:=0.749; hv[14]:=0.0639; } \\
& h c[15]:=0.8 ; \quad h v[15]:=0.0686 \text {; } \\
& \mathrm{hc}[16]:=0.85 ; \quad \mathrm{hv}[16]:=0.0731 \text {; } \\
& \mathrm{hc}[17]:=0.9 ; \quad \mathrm{hv}[17]:=0.0783 ; \\
& \mathrm{hc}[18]:=0.95 ; \quad \mathrm{hv}[18]:=0.0836 \text {; } \\
& \mathrm{hc}[19]:=1 ; \quad \mathrm{hv}[19]:=0.0884 \text {; } \\
& \mathrm{hc}[20]:=1.05 ; \quad \mathrm{hv}[20]:=0.0935 ; \\
& \mathrm{hc}[21]:=1.1 ; \quad \mathrm{hv}[21]:=0.0992 \text {; }
\end{aligned}
$$


$h c[22]:=1.15 ; \quad h v[22]:=0.1065$

$\mathrm{hc}[23]:=1.2 ; \quad \mathrm{hv}[23]:=0.1112$;

$\mathrm{hc}[24]:=1.25 ; \quad \mathrm{hv}[24]:=0.1162 ;$

$\mathrm{hc}[25]:=1.3 ; \quad \mathrm{hv}[25]:=0.1238 ;$

$\mathrm{hc}[26]:=1.349 ; \quad \mathrm{hv}[26]:=0.1274 ;$

$\mathrm{hc}[27]:=1.4 ; \quad \mathrm{hv}[27]:=0.1324$;

$\mathrm{hc}[28]:=1.45 ; \quad \operatorname{hv}[28]:=0.135 ;$

$\mathrm{hc}[29]:=1.5 ; \quad \mathrm{hv}[29]:=0.1395 ;$

$\mathrm{hc}[30]:=1.55 ; \quad \mathrm{hv}[30]:=0.1441 ;$

$\mathrm{hc}[31]:=1.6 ; \quad \mathrm{hv}[31]:=0.1483 ;$

hc[32]:=1.65; hv[32]:=0.1527;

hc[33]:=1.7; $\quad$ hv[33]:=0.1552;

$\mathrm{hc}[34]:=1.75 ; \quad \mathrm{hv[34]}:=0.1598 ;$

$\mathrm{hc}[35]:=1.8 ; \quad \mathrm{hv[35]:=0.1639;}$

$\mathrm{hc}[36]:=1.85 ; \quad \mathrm{hv}[36]:=0.1684$

hc[37]:=1.9; $\quad \operatorname{hv[37]:=0.173;}$

hc[38]:=1.95; hv[38]:=0.1778;

hc[39]:=2; $\quad$ hv[39]:=0.1838;

$\mathrm{hc}[40]:=2.05 ; \quad \mathrm{hv}[40]:=0.1865 ;$

$h c[41]:=2.1 ; \quad \operatorname{hv[41]:=0.191;}$

hc[42]:=2.15; hv[42]:=0.1953; 


$$
\begin{aligned}
& h c[43]:=2.2 ; \quad h v[43]:=0.215 \\
& \text { hc[44]:=2.25; } \operatorname{hv[44]:=0.219;} \\
& \mathrm{hc}[45]:=2.3 ; \quad \mathrm{hv}[45]:=0.225 \text {; } \\
& \text { hc[46]:=2.35; hv[46]:=0.23; } \\
& h c[47]:=2.4 ; \quad h v[47]:=0.235 \\
& \text { hc[48]:=2.46; } \mathrm{hv[48]:=0.241;} \\
& h c[49]:=2.5 ; \quad h v[49]:=0.246 \text {; } \\
& h c[50]:=2.55 ; \quad h v[50]:=0.251 ; \\
& \mathrm{hc}[51]:=2.6 ; \quad \operatorname{hv}[51]:=0.256 \text {; } \\
& \text { hc[52]:=2.65; } \quad \text { hv[52]:=0.261; } \\
& h c[53]:=2.7 ; \quad h v[53]:=0.266 \text {; } \\
& \text { hc[54]:=2.74; } \quad \text { hv[54]:=0.271; } \\
& \mathrm{hc}[55]:=2.8 ; \quad \operatorname{hv}[55]:=0.276 \text {; } \\
& \mathrm{hc}[56]:=2.85 ; \quad \mathrm{hv}[56]:=0.282 \text {; } \\
& h c[57]:=2.88 ; \quad h v[57]:=0.285 ; \\
& h c[58]:=2.9 ; \quad \text { hv[58]:=0.288; } \\
& \text { hc[59]:=2.95; } \quad \text { hv[59]:=0.291; } \\
& \text { hc[60]:=3; } \quad \text { hv[60]:=0.296; } \\
& \text { hc[61]:=3.05; } \quad \text { hv[61]:=0.303; } \\
& \text { hc[62]:=3.1; } \quad \text { hv[62]:=0.308; } \\
& \mathrm{vc}[1]:=0.099 ; \quad \mathrm{vv}[1]:=0.0079
\end{aligned}
$$




$$
\begin{aligned}
& \mathrm{vc}[2]:=0.15 ; \quad \mathrm{vv}[2]:=0.012 \\
& \mathrm{vc}[3]:=0.199 ; \quad \operatorname{vv[3]:=0.016;} \\
& \mathrm{vc}[4]:=0.251 ; \quad \mathrm{vv}[4]:=0.0202 ; \\
& \mathrm{vc}[5]:=0.3 ; \quad \operatorname{vv}[5]:=0.0242 \\
& v c[6]:=0.351 ; \quad v v[6]:=0.0284 \text {; }
\end{aligned}
$$

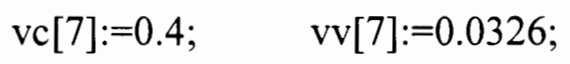

$$
\begin{aligned}
& \mathrm{vc}[8]:=0.45 ; \quad \mathrm{vv}[8]:=0.037 \text {; } \\
& \mathrm{vc}[9]:=0.5 ; \quad \operatorname{vv}[9]:=0.0413 \text {; } \\
& \mathrm{vc}[10]:=0.55 ; \quad \mathrm{vv}[10]:=0.0457 \text {; } \\
& \operatorname{vc}[11]:=0.6 ; \quad \operatorname{vv}[11]:=0.0503 \text {; } \\
& \operatorname{vc}[12]:=0.649 ; \quad \operatorname{vv}[12]:=0.0548 ; \\
& \operatorname{vc}[13]:=0.7 ; \quad \operatorname{vv}[13]:=0.0593 \text {; } \\
& \operatorname{vc}[14]:=0.75 ; \quad \operatorname{vv}[14]:=0.064 \\
& \mathrm{vc}[15]:=0.8 ; \quad \mathrm{vv}[15]:=0.0694 \\
& \operatorname{vc}[16]:=0.85 ; \quad \operatorname{vv}[16]:=0.0744 \\
& v c[17]:=0.9 ; \quad v v[17]:=0.0794 \text {; } \\
& \mathrm{vc}[18]:=0.951 ; \quad \operatorname{vv}[18]:=0.0846 \text {; } \\
& \mathrm{vc}[19]:=1 ; \quad \operatorname{vv}[19]:=0.0895 \\
& \mathrm{vc}[20]:=1.05 ; \quad \mathrm{vv}[20]:=0.0952 ; \\
& \mathrm{vc}[21]:=1.099 ; \quad \mathrm{vv}[21]:=0.0944 ; \\
& \operatorname{vc}[22]:=1.15 ; \quad \operatorname{vv}[22]:=0.099 \text {; }
\end{aligned}
$$




$$
\begin{aligned}
& \mathrm{vc}[23]:=1.2 ; \quad \operatorname{vv}[23]:=0.1034 \\
& \mathrm{vc}[24]:=1.25 ; \quad \mathrm{vv}[24]:=0.1084 ; \\
& \mathrm{vc}[25]:=1.3 ; \quad \operatorname{vv}[25]:=0.1124 \\
& \mathrm{vc}[26]:=1.35 ; \quad \mathrm{vv}[26]:=0.1171 \text {; } \\
& \operatorname{vc}[27]:=0 ; \quad \operatorname{vv[27]:=0;} \\
& \operatorname{vc}[28]:=1.4 ; \quad \operatorname{vv}[28]:=0.1215 \text {; } \\
& \mathrm{vc}[29]:=1.45 ; \quad \mathrm{vv}[29]:=0.1258 \text {; } \\
& \mathrm{vc}[30]:=1.499 ; \quad \operatorname{vv}[30]:=0.1301 ; \\
& v c[31]:=1.55 ; \quad \operatorname{vv}[31]:=0.1352 \\
& \mathrm{vc}[32]:=1.599 ; \quad \mathrm{vv}[32]:=0.1396 \text {; } \\
& \operatorname{vc}[33]:=0 ; \quad \operatorname{vv}[33]:=0 ; \\
& \mathrm{vc}[34]:=1.652 ; \quad \mathrm{vv}[34]:=0.1447 \text {; } \\
& \operatorname{vc}[35]:=1.701 ; \quad \operatorname{vv}[35]:=0.149 ; \\
& \operatorname{vc}[36]:=1.753 ; \quad \operatorname{vv}[36]:=0.1533 \text {; } \\
& \operatorname{vc}[37]:=1.8 ; \quad \operatorname{vv}[37]:=0.1583 ; \\
& \mathrm{vc}[38]:=1.85 ; \quad \operatorname{vv}[38]:=0.1628 ; \\
& \operatorname{vc}[39]:=1.9 ; \quad \operatorname{vv}[39]:=0.1675 \text {; } \\
& \mathrm{vc}[40]:=1.95 ; \quad \operatorname{vv}[40]:=0.1723 ; \\
& \operatorname{vc}[41]:=2 ; \quad \operatorname{vv}[41]:=0.1778 ; \\
& \operatorname{vc}[42]:=2.05 ; \quad \operatorname{vv}[42]:=0.196 \text {; } \\
& \operatorname{vc}[43]:=2.1 ; \quad \operatorname{vv}[43]:=0.201 ;
\end{aligned}
$$




$$
\begin{aligned}
& \mathrm{vc}[44]:=2.15 ; \quad \mathrm{vv}[44]:=0.206 \\
& \mathrm{vc}[45]:=2.2 ; \quad \mathrm{vv}[45]:=0.211 \\
& \mathrm{vc}[46]:=2.25 ; \quad \mathrm{vv}[46]:=0.216 \\
& \mathrm{vc}[47]:=2.3 ; \quad \mathrm{vv}[47]:=0.221 \text {; } \\
& \mathrm{vc}[48]:=2.35 ; \quad \mathrm{vv}[48]:=0.226 \\
& \operatorname{vc}[49]:=2.4 ; \quad \operatorname{vv}[49]:=0.232 \\
& \operatorname{vc}[50]:=2.44 ; \quad \operatorname{vv}[50]:=0.235 \\
& \operatorname{vc}[51]:=2.48 ; \quad \operatorname{vv}[51]:=0.24 \\
& \mathrm{vc}[52]:=2.52 ; \quad \mathrm{vv}[52]:=0.244 \\
& \operatorname{vc}[53]:=2.56 ; \quad \operatorname{vv}[53]:=0.248 \\
& \mathrm{vc}[54]:=2.6 ; \quad \mathrm{vv}[54]:=0.253 \\
& \mathrm{vc}[55]:=2.64 ; \quad \mathrm{vv}[55]:=0.257 \\
& \mathrm{vc}[56]:=2.68 ; \quad \mathrm{vv}[56]:=0.261 \\
& \mathrm{vc}[57]:=2.72 ; \quad \mathrm{vv}[57]:=0.265 \\
& \operatorname{vc}[58]:=2.76 ; \quad \operatorname{vv}[58]:=0.269 \\
& \mathrm{vc}[59]:=2.8 ; \quad \mathrm{vv}[59]:=0.273 \\
& \mathrm{vc}[60]:=2.84 ; \quad \operatorname{vv}[60]:=0.278 \\
& \mathrm{vc}[61]:=2.88 ; \quad \operatorname{vv}[61]:=0.282 \\
& \mathrm{vc}[62]:=2.92 ; \quad \mathrm{vv}[62]:=0.287 \\
& \operatorname{vc}[63]:=0 ; \quad \operatorname{vv}[63]:=0 \text {; } \\
& \mathrm{vc}[64]:=2.96 ; \quad \mathrm{vv}[64]:=0.291
\end{aligned}
$$




$$
\begin{aligned}
& \text { vc[65]:=3; vv[65]:=0.294; } \\
& \text { hc[4]:=0.25;hv[4]:=0.0201; } \\
& \text { hc[6]:=0.351;hv[6]:=0.0284; } \\
& \text { hc[8]:=0.45;hv[8]:=0.0367; } \\
& \text { hc[9]:=0.5;hv[9]:=0.041; } \\
& \text { hc[11]:=0.6;hv[11]:=0.0495; } \\
& \text { hc[13]:=0.7;hv[13]:=0.0586; } \\
& \text { hc[15]:=0.799;hv[15]:=0.0676; } \\
& \text { hc[17]:=0.9;hv[17]:=0.0775; } \\
& \text { hc[19]:=1.0;hv[19]:=0.0880; } \\
& \text { hc[21]:=1.1;hv[21]:=0.0972; } \\
& \text { hc[22]:=1.15;hv[22]:=0.105; } \\
& \text { hc[23]:=1.201;hv[23]:=0.109; } \\
& \text { hc[26]:=1.35;hv[26]:=0.123; } \\
& \text { hc[27]:=1.4; hv[27]:=0.125; } \\
& \text { hc[28]:=1.45;hv[28]:=0.131; } \\
& \text { hc[30]:=1.55;hv[30]:=0.139; } \\
& \text { hc[31]:=1.6;hv[31]:=0.143; } \\
& \text { hc[32]:=1.65;hv[32]:=0.147; } \\
& \text { hc[33]:=1.7;hv[33]:=0.152; }
\end{aligned}
$$




$$
\begin{aligned}
& \text { hc[34]:=1.75; hv[34]:=0.157; } \\
& \mathrm{hc}[35]:=1.8 ; \mathrm{hv}[35]:=0.16 \text {; } \\
& \mathrm{hc}[36]:=1.85 ; \mathrm{hv}[36]:=0.166 \text {; } \\
& \text { hc[37]:=1.9; hv[37]:=0.172; } \\
& \text { hc[38]:=1.951;hv[38]:=0.175; } \\
& \text { hc[39]:=2.0; hv[39]:=0.181; } \\
& \mathrm{hc}[40]:=2.2 ; \mathrm{hv}[40]:=0.2 \text {; } \\
& \mathrm{hc}[41]:=2.3 ; \mathrm{hv}[41]:=0.209 \text {; } \\
& \text { hc[42]:=2.4; hv[42]:=0.219; } \\
& \text { hc[43]:=2.55;hv[43]:=0.223; } \\
& h c[44]:=2.65 ; h v[44]:=0.243 \text {; } \\
& \text { hc[45]:=2.75;hv[45]:=0.252; } \\
& \mathrm{hc}[46]:=2.8 ; \mathrm{hv}[46]:=0.257 \text {; } \\
& \mathrm{hc}[47]:=2.85 ; \mathrm{hv}[47]:=0.261 \text {; } \\
& \text { hc }[48]:=2.9 ; \mathrm{hv}[48]:=0.266 \text {; } \\
& \text { hc[49]:=3.0; hv[49]:=0.275; } \\
& \mathrm{hc}[50]:=3.05 ; \mathrm{hv}[50]:=0.281 \text {; } \\
& \mathrm{hc}[51]:=3.08 ; \mathrm{hv}[51]:=0.286 \text {; } \\
& \text { hc[52]:=3.15;hv[52]:=0.291; } \\
& \text { hc[53]:=3.2; hv[53]:=0.295; } \\
& \operatorname{vc}[3]:=0.2 ; \mathrm{vv}[3]:=0.016 \text {; }
\end{aligned}
$$




$$
\begin{aligned}
& \mathrm{vc}[5]:=0.3 ; \mathrm{vv}[5]:=0.0242 \\
& \mathrm{vc}[7]:=0.4 ; \mathrm{vv}[7]:=0.0325 \\
& \mathrm{vc}[10]:=0.549 ; \mathrm{vv}[10]:=0.0457 \\
& \mathrm{vc}[12]:=0.65 ; \mathrm{vv}[12]:=0.055 \\
& \mathrm{vc}[14]:=0.75 ; \mathrm{vv}[14]:=0.064 \\
& \mathrm{vc}[16]:=0.85 ; \mathrm{vv}[16]:=0.0732 \text {; } \\
& \mathrm{vc}[18]:=0.951 ; \mathrm{vv}[18]:=0.0832 \\
& \operatorname{vc}[20]:=1.05 ; \mathrm{vv}[20]:=0.0945 ; \\
& \operatorname{vc}[24]:=1.25 ; \mathrm{vv}[24]:=0.123 \text {; } \\
& \mathrm{vc}[25]:=1.3 ; \mathrm{vv}[25]:=0.112 \text {; } \\
& \operatorname{vc}[29]:=1.5 ; \mathrm{vv}[29]:=0.129 \text {; } \\
& \operatorname{vc}[30]:=1.55 ; \operatorname{vv}[30]:=0.135 \text {; } \\
& \operatorname{vc}[31]:=1.6 ; \operatorname{vv}[31]:=0.14 \\
& \operatorname{vc}[32]:=1.65 ; \operatorname{vv}[32]:=0.144 ; \\
& \operatorname{vc}[33]:=1.7 ; \mathrm{vv}[33]:=0.148 \\
& \operatorname{vc}[34]:=1.75 ; \mathrm{vv}[34]:=0.154 \text {; } \\
& \mathrm{vc}[35]:=1.8 ; \mathrm{vv}[35]:=0.158 \\
& \mathrm{vc}[36]:=1.853 ; \mathrm{vv}[36]:=0.163 ; \\
& \mathrm{vc}[37]:=1.9 ; \mathrm{vv}[37]:=0.166 \\
& \operatorname{vc}[38]:=1.95 ; \operatorname{vv}[38]:=0.174 ; \\
& \mathrm{vc}[39]:=2.0 ; \mathrm{vv}[39]:=0.177 \text {; }
\end{aligned}
$$




$$
\begin{aligned}
& \operatorname{vc}[40]:=2.2 ; \operatorname{vv}[40]:=0.196 ; \\
& \operatorname{vc}[41]:=2.3 ; \operatorname{vv}[41]:=0.205 ; \\
& \operatorname{vc}[42]:=2.4 ; \operatorname{vv}[42]:=0.216 ; \\
& \operatorname{vc}[43]:=2.45 ; \operatorname{vv}[43]:=0.221 ; \\
& \operatorname{vc}[44]:=2.5 ; \operatorname{vv}[44]:=0.225 ; \\
& \operatorname{vc}[45]:=2.56 ; \operatorname{vv}[45]:=0.23 ; \\
& \operatorname{vc}[47]:=2.66 ; \operatorname{vv}[47]:=0.236 ; \\
& \operatorname{vc}[48]:=2.71 ; \operatorname{vv}[48]:=0.241 ; \\
& \operatorname{vc}[49]:=2.8 ; \operatorname{vv}[49]:=0.251 ; \\
& \operatorname{vc}[50]:=2.96 ; \operatorname{vv}[50]:=0.266 ; \\
& \operatorname{vc}[51]:=3.03 ; \operatorname{vv}[51]:=0.272 ; \\
& \}
\end{aligned}
$$

assign(Fvar1,'c:|bill|v1');

rewrite(Fvar1);

$$
\text { for } y y:=1 \text { to } 65 \text { do }
$$

begin

$\operatorname{str}(\mathrm{yy}, \mathrm{s} 2)$

Fname:='g:|userlerik $\mid v \backslash^{\prime}+s 2+$ 'v.prn';

assign(Fvar,Fname);

$\{\$ I-\}$

reset(Fvar); 
$\{\$ i+\}$

if (IOresult $=0$ ) then

begin

writeln(' Enter filename -...-> ', Fname);

$\{\quad$ write(' Enter current -...> ');

readln(current);

\} current: $=v c[y y] / 0.875$;

\{ write(' Enter V abs $\quad-. .->$ ');

readin(Power);

writeln;

\} Power:=vv[yy];

resist:=Power/current;

writeln(' Current -...-> ',current);

Power:=Power*current/0.1148;

sample:=4.0;

writeln(' Power -----.-> ',Power);

$\operatorname{assign}($ Fvar,Fname);

reset(fvar);

for $z z:=1$ to 4 do

begin

new $(Q)$; 
$\operatorname{new}(\mathrm{T})$

INIT;

TEMPERATURE;

FLUX;

AREA;

Dispose(T);

Dispose(Q);

writeln(Fvar1,Fname,' ',resist,' ',Power,' ',current,' ',Anet,' ',avg,' ',minQ,'

',maxQ,' ',minT,' ',maxT);

end;

$\operatorname{close}($ Fvar)

end; $\{$ IOresult $\}$

end; $\{y y\}$

close(Fvar1); 